\title{
Near-Surface Monitoring Strategies for Geologic Carbon Dioxide Storage Verification
}

\author{
Curtis M. Oldenburg \\ Jennifer L. Lewicki \\ Robert P. Hepple
}

Earth Sciences Division

Ernest Orlando Lawrence Berkeley National Laboratory

Berkeley, CA 94720

October 30, 2003 


\section{DISCLAIMER}

This report was prepared as an account of work sponsored by an agency of the United States Government. Neither the United States Government nor any agency thereof, nor any of their employees, makes any warranty, express or implied, or assumes any legal liability or responsibility for the accuracy, completeness, or usefulness of any information, apparatus, product, or process disclosed, or represents that its use would not infringe privately held rights. Reference herein to any specific commercial product, process, or service by trade name, trademark, manufacturer, or otherwise does not necessarily constitute or imply its endorsement, recommendation, or favoring by the United States Government or any agency thereof. The views and opinions of authors expressed herein do not necessarily state or reflect those of the United States Government or any agency thereof. 


\section{TABLE OF CONTENTS}

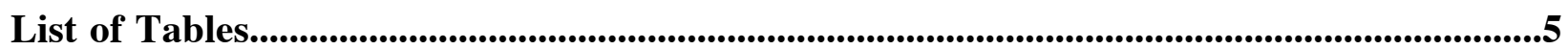

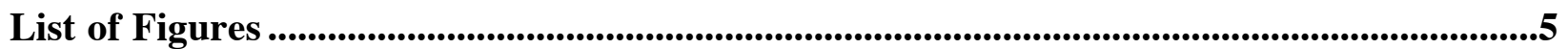

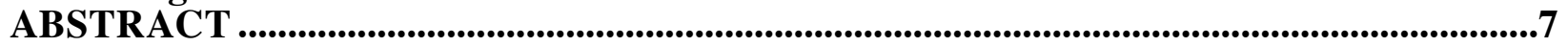

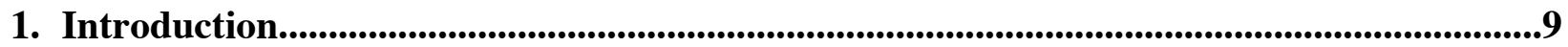

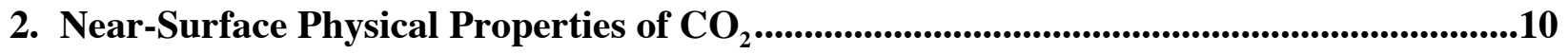

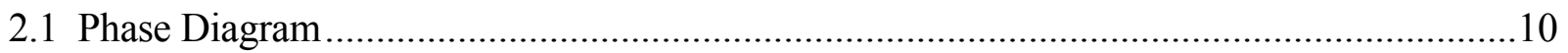

2.2 Transport Properties.................................................................................................

3. Controls on the $\mathrm{CO}_{2}$ Leakage or Seepage Signal (LOSS).............................................11

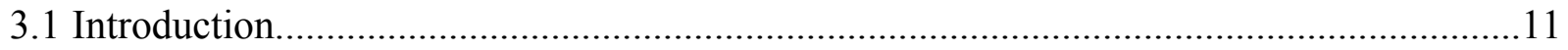

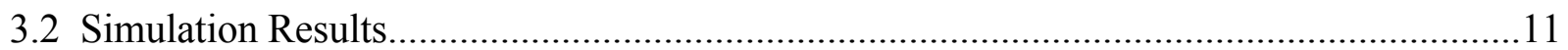

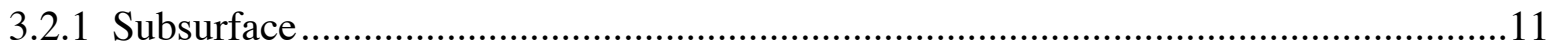

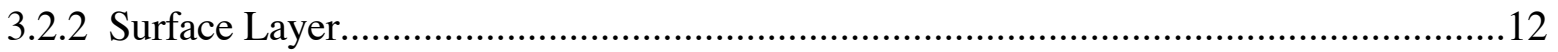

4. Controls on Background Fluxes and Concentrations......................................................................12

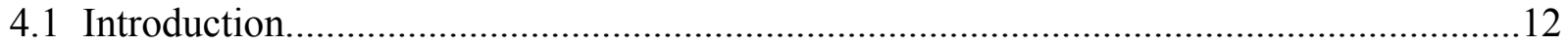

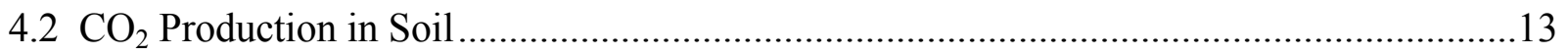

$4.3 \mathrm{CO}_{2}$ from Deep Sources ......................................................................................13

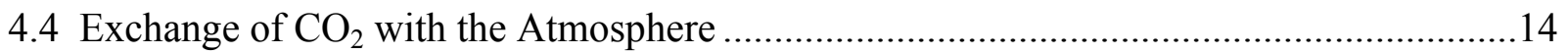

5. Review of Near-Surface $\mathrm{CO}_{2}$ Monitoring Technologies.................................................................14

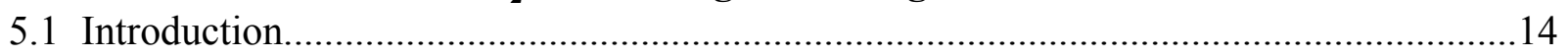

5.2 Conventional $\mathrm{CO}_{2}$ Monitoring Technologies .................................................................. 14

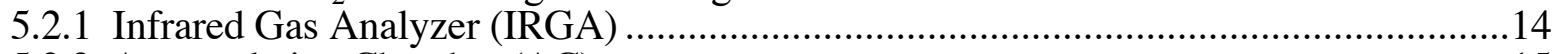

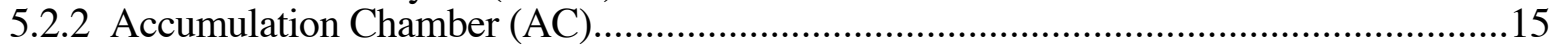

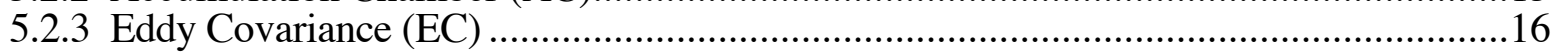

5.2.4 Light Detection and Range Finding (LIDAR) ..........................................................17

5.3 Unconventional $\mathrm{CO}_{2}$ Monitoring Technologies............................................................18

5.3.1 Hyperspectral Imaging of Vegetative Stress..........................................................18

5.3.2 Long Open Path IR and Tunable Lasers ..............................................................19

5.3.3 Micro-Electronic Mechanical Systems (MEMS), Smart Dust, Motes.............................19

5.3.4 Animal Detectors ..........................................................................................

6. Strategies for $\mathrm{CO}_{2}$ Storage Verification .........................................................................................20

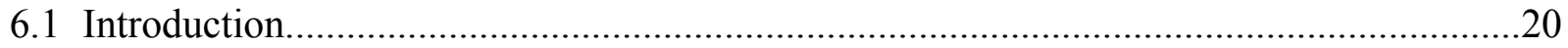

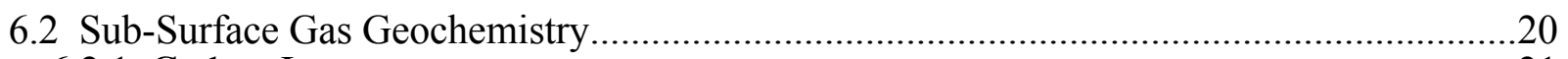

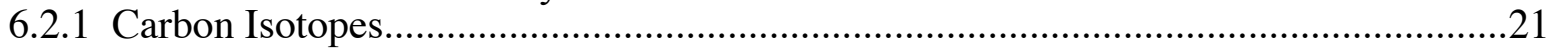

6.2.2 Bulk Soil Gas Composition.........................................................................................22

6.2.3 Measurement Strategies ............................................................................................23

6.3 Surface $\mathrm{CO}_{2}$ Concentration and Flux Monitoring ………..............................................24

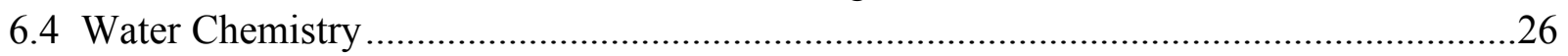

6.5 Refinement of Geochemical Sampling Using Statistical Analysis.....................................2

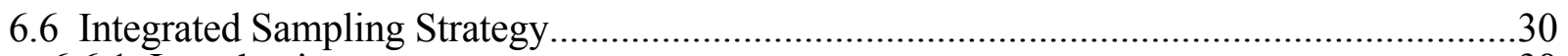

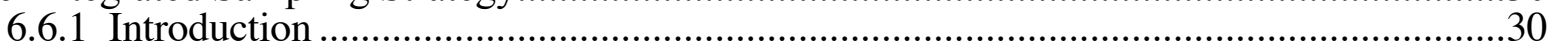

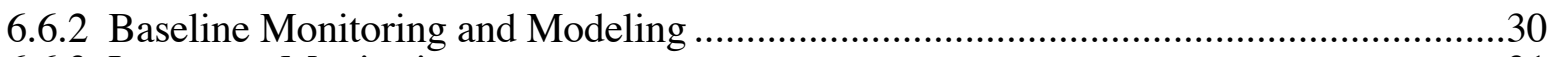

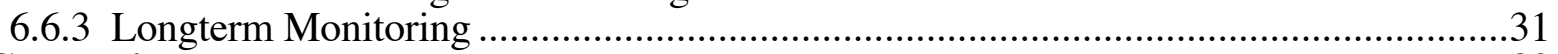

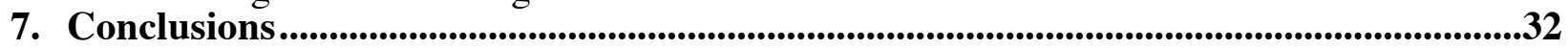

Acknowledgments...................................................................................................................................33

References .....................................................................................................................................................33 
This page left intentionally blank. 


\section{LIST OF TABLES}

Table 3.1. Hydrogeological properties of the unsaturated zone for the base case......................39

Table 3.2. Properties of the coupled subsurface-surface-layer model system.........................39

Table 6.1. Chemical and isotopic signatures related to $\mathrm{CO}_{2}$ derived from different sources.........40

\section{LIST OF FIGURES}

Figure 2.1. Phase diagram for $\mathrm{CO}_{2}$ showing typical P-T path with depth in the earth. 41

Figure 2.2. Density as a function of concentration in the system $\mathrm{CO}_{2}$-air. ...........................42

Figure 2.3. Viscosity as a function of concentration in the system $\mathrm{CO}_{2}$-air...........................43

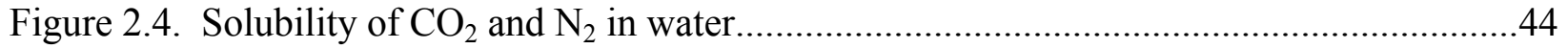

Figure 3.1. Simulation results for leakage. ........................................................................45

Figure 3.2. Maximum seepage flux of $\mathrm{CO}_{2}$ and maximum near-surface mole fraction $\mathrm{CO}_{2} \ldots \ldots . . .46$

Figure 3.3. Simulation results for the coupled problem .....................................................47

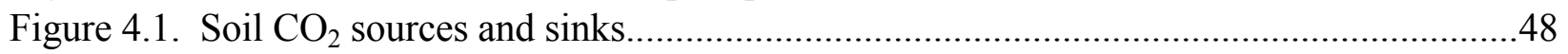

Figure 4.2. Repeated soil $\mathrm{CO}_{2}$ concentration profiles .......................................................49

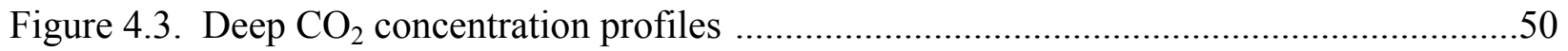

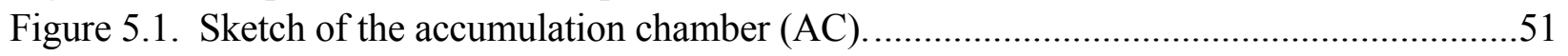

Figure 5.2. Sketch of eddy correlation (EC) instrumentation tower. ......................................52

Figure 5.3. Sketch of truck-mounted LIDAR system and seepage plume.................................53

Figure 6.1. Example activity and schedule chart for $\mathrm{CO}_{2}$ LOSS detection and monitoring..........54 
This page left intentionally blank. 


\section{ABSTRACT}

Geologic carbon sequestration is the capture of anthropogenic carbon dioxide $\left(\mathrm{CO}_{2}\right)$ and its storage in deep geologic formations. Geologic $\mathrm{CO}_{2}$ storage verification will be needed to ensure that $\mathrm{CO}_{2}$ is not leaking from the intended storage formation and seeping out of the ground. Because the ultimate failure of geologic $\mathrm{CO}_{2}$ storage occurs when $\mathrm{CO}_{2}$ seeps out of the ground into the atmospheric surface layer, and because elevated concentrations of $\mathrm{CO}_{2}$ near the ground surface can cause health, safety, and environmental risks, monitoring will need to be carried out in the near-surface environment.

The detection of a $\mathrm{CO}_{2}$ leakage or seepage signal (LOSS) in the near-surface environment is challenging because there are large natural variations in $\mathrm{CO}_{2}$ concentrations and fluxes arising from soil, plant, and subsurface processes. The term leakage refers to $\mathrm{CO}_{2}$ migration away from the intended storage site, while seepage is defined as $\mathrm{CO}_{2}$ passing from one medium to another, for example across the ground surface. The flow and transport of $\mathrm{CO}_{2}$ at high concentrations in the near-surface environment will be controlled by its high density, low viscosity, and high solubility in water relative to air. Numerical simulations of leakage and seepage show that $\mathrm{CO}_{2}$ concentrations can reach very high levels in the shallow subsurface even for relatively modest $\mathrm{CO}_{2}$ leakage fluxes. However, once $\mathrm{CO}_{2}$ seeps out of the ground into the atmospheric surface layer, surface winds are effective at dispersing $\mathrm{CO}_{2}$ seepage.

In natural ecological systems with no $\mathrm{CO}_{2}$ LOSS, near-surface $\mathrm{CO}_{2}$ fluxes and concentrations are controlled by $\mathrm{CO}_{2}$ uptake by photosynthesis, and production by root respiration, organic carbon biodegradation in soil, deep outgassing of $\mathrm{CO}_{2}$, and by exchange of $\mathrm{CO}_{2}$ with the atmosphere. Existing technologies available for monitoring $\mathrm{CO}_{2}$ in the near-surface environment include (1) the infrared gas analyzer (IRGA) for measuring point concentrations using IR absorption by the $\mathrm{CO}_{2}$ molecule, (2) the accumulation chamber (AC) method for measuring soil $\mathrm{CO}_{2}$ fluxes at discrete points, (3) the eddy correlation (EC) tower that measures net flux over a given area, and (4) light distancing and ranging (LIDAR) that can measure $\mathrm{CO}_{2}$ concentrations over an integrated path. Novel technologies that could potentially be useful for $\mathrm{CO}_{2}$ concentration and flux measurement include hyperspectral remote sensing of vegetative stress as an indication of elevated $\mathrm{CO}_{2}$ concentrations, tunable lasers for long distance integrated concentration measurements, microelectronic mechanical systems (MEMS) that can be dispersed to make widespread point measurements, and trained animals such as dogs as used for landmine detection.

Although advanced technologies exist for detecting $\mathrm{CO}_{2}$ concentrations and fluxes, technology alone cannot solve the fundamental problem in $\mathrm{CO}_{2}$ storage verification which is to discern the $\mathrm{CO}_{2}$ LOSS from natural background variability. To address this challenge, we propose an integrated measurement, monitoring, and modeling strategy. The initial effort at a potential geologic $\mathrm{CO}_{2}$ storage site should be directed at characterizing the soils, plants, and subsurface hydrogeologic system to develop a conceptual model of natural carbon cycling and to direct monitoring toward geologic features expected to act as conduits for $\mathrm{CO}_{2}$ leakage. Also, the natural spatial and temporal variability of surface and subsurface $\mathrm{CO}_{2}$ fluxes (using the $\mathrm{AC}$ and EC methods), concentrations (using a portable IRGA), and isotopic compositions should be well 
characterized. During and following $\mathrm{CO}_{2}$ injection into the storage reservoir, point measurements of soil $\mathrm{CO}_{2}$ fluxes and concentrations using the $\mathrm{AC}$ method and a portable IRGA, respectively, and integrated measurements of flux using $\mathrm{EC}$ are proposed to detect potential areas of $\mathrm{CO}_{2}$ LOSS. Statistical analyses of measurement data can be used to guide sampling strategy, discern patterns that may be indicative of $\mathrm{CO}_{2}$ LOSS from the natural spatial variability of the data, and assess the presence (or absence) of $\mathrm{CO}_{2}$ LOSS with a desired confidence level. If needed, more expensive vertical soil gas sampling and chemical and isotopic gas analyses can be undertaken in areas of high surface $\mathrm{CO}_{2}$ flux and soil $\mathrm{CO}_{2}$ concentration to determine if $\mathrm{CO}_{2}$ is derived from a deep fossil-fuel source, as would be the case for $\mathrm{CO}_{2}$ LOSS from the geologic storage reservoir. The site characterization and monitoring will be integrated with ecological and flow and transport modeling to gain a better understanding and predictive capability of the $\mathrm{CO}_{2}$ flow and transport in the system. Deviations from expectations in either the field monitoring or modeling results will direct further investigations and analysis to discern any potential $\mathrm{CO}_{2} \mathrm{LOSS}$. 


\section{INTRODUCTION}

Geologic carbon sequestration is the capture of anthropogenic $\mathrm{CO}_{2}$, typically separated from industrial and power-plant flue gases, and its storage in deep underground formations such as depleted oil and gas reservoirs and deep brine-filled formations. The purpose of geologic carbon sequestration is to reduce net atmospheric emissions of $\mathrm{CO}_{2}$ to mitigate potential climate change associated with the role of $\mathrm{CO}_{2}$ as a greenhouse gas. In order to ensure that geologic $\mathrm{CO}_{2}$ storage is effective, monitoring of $\mathrm{CO}_{2}$ storage sites will have to be carried out to verify that $\mathrm{CO}_{2}$ is not leaking from the intended storage site, migrating to the near-surface environment, and seeping out of the ground. Carbon dioxide fluxes to the shallow subsurface from leaking storage sites may be small and difficult to detect, yet still represent a significant loss of $\mathrm{CO}_{2}$ over the several-hundredyear time scales needed for $\mathrm{CO}_{2}$ storage to be effective against climate change (Hepple and Benson, 2002). Because the ultimate failure of $\mathrm{CO}_{2}$ storage occurs when $\mathrm{CO}_{2}$ seeps out of the ground, the near-surface environment encompassing the shallow subsurface and atmospheric surface layer are key regions in which storage verification must be carried out. In addition, monitoring in this region is important because elevated near-surface $\mathrm{CO}_{2}$ concentrations may be a hazard to humans, plants, and animals. As in prior work (Oldenburg and Unger, 2003), we use the term leakage to refer to $\mathrm{CO}_{2}$ migration away from the intended storage site, while seepage is defined as $\mathrm{CO}_{2}$ passing from one medium to another, for example across the ground surface, into surface water, or into a subsurface vault or basement.

Verification of geologic $\mathrm{CO}_{2}$ storage in the near-surface environment involves monitoring a system with large variation in $\mathrm{CO}_{2}$ fluxes and concentrations arising from natural biological and hydrologic processes. These natural variations are a result of plant photosynthesis, root respiration, biological processes in soil, and natural $\mathrm{CO}_{2}$ outgassing from deep sources. The $\mathrm{CO}_{2}$ storage reservoirs will be chosen in large part for their very low probability of $\mathrm{CO}_{2}$ leakage away from the target formation within several hundred- to thousand-year time scales. As a result, seepage detection will involve searching for potential $\mathrm{CO}_{2}$ anomalies, likely of small magnitude, over areas of tens of $\mathrm{km}^{2}$ or more. The challenge of geologic $\mathrm{CO}_{2}$ storage verification in the nearsurface environment is discerning a small $\mathrm{CO}_{2}$ Leakage or Seepage Signal (LOSS) from the naturally varying background $\mathrm{CO}_{2}$ fluxes and concentrations.

The purpose of this report is to discuss $\mathrm{CO}_{2}$ storage verification by monitoring and analysis of the near-surface environment. To this end, we (1) present a discussion of the properties of $\mathrm{CO}_{2}$ and implications for $\mathrm{CO}_{2}$ transport in the near-surface region, (2) summarize model simulations of $\mathrm{CO}_{2}$ leakage and seepage that establish some fundamental features of the process, (3) present a summary of processes that affect natural background $\mathrm{CO}_{2}$ fluxes and concentrations within which the LOSS will have to be discerned, (4) present a summary of instrumentation that is currently available or potentially available in the future to monitor $\mathrm{CO}_{2}$ leakage and seepage in the nearsurface environment, and (5) discuss potential strategies and approaches that use existing instrumentation to discern $\mathrm{CO}_{2}$ LOSS from the naturally varying background fluxes and concentrations associated with the carbon cycle. Although the use of artificial tracers is being 
considered for use in leakage and seepage detection, uncertainty surrounding the choice of tracer, subsurface processes affecting tracer transport, potential for surface contamination during injection operations, and the added cost of large quantities of tracer led us to focus on monitoring and detection of $\mathrm{CO}_{2}$ itself.

\section{NEAR-SURFACE PHYSICAL PROPERTIES OF $\mathrm{CO}_{2}$}

\subsection{Phase Diagram}

In this section, we discuss the physical properties of $\mathrm{CO}_{2}$ with an emphasis on the contrast in properties of $\mathrm{CO}_{2}$ relative to water and air in the shallow subsurface. Carbon dioxide is a colorless and odorless gas with critical pressure $\left(P_{c}\right)$ equal to 73.8 bars and critical temperature $\left(T_{c}\right)$ equal to $31{ }^{\circ} \mathrm{C}$. We present in Figure 2.1 the phase diagram for $\mathrm{CO}_{2}$ showing the gaseous, liquid, solid, and supercritical regions along with an approximate curve representing a $P-T$ path in the subsurface assuming hydrostatic pressure and a $25{ }^{\circ} \mathrm{C} \mathrm{km}^{-1}$ geothermal gradient and $15{ }^{\circ} \mathrm{C}$ ground-surface temperature. As shown in Figure 2.1, the geothermal gradient ensures that $\mathrm{CO}_{2}$ will be typically supercritical in the subsurface at depths greater than approximately $800 \mathrm{~m}$, and gaseous in the shallow subsurface and atmospheric surface layer.

\subsection{Transport Properties}

The shallow subsurface, for example near the water table and within the vadose zone, is characterized by pressures and temperatures approximately equal to those at the ground surface, i.e., ambient atmospheric conditions. We present in Figure 2.2 the density of $\mathrm{CO}_{2}$-air mixtures as a function of mole fraction at three different temperatures (Magee et al., 1994; NIST, 1992). Air is assumed here to be dry and composed of $79 \%$ nitrogen $\left(\mathrm{N}_{2}\right)$ and $21 \%$ oxygen $\left(\mathrm{O}_{2}\right)$ by volume. As shown in Figure 2.2, $\mathrm{CO}_{2}$ is a dense gas relative to dry air, and the gases mix approximately ideally at atmospheric pressure. Note that the contrast in density between pure $\mathrm{CO}_{2}$ and air will be larger in the vadose zone because of the presence of water vapor, which is less dense than dry air due to the smaller molecular weight of water $\left(18.0 \mathrm{~g} \mathrm{~mole}^{-1}\right)$ relative to dry air $\left(28.96 \mathrm{~g} \mathrm{~mole}^{-1}\right)$.

We present in Figure 2.3 the viscosity variation of $\mathrm{CO}_{2}$-air mixtures at the same conditions (Magee et al., 1994; NIST, 1992). As shown, $\mathrm{CO}_{2}$ is less viscous than air, a somewhat nonintuitive relation given the contrast in density. For comparison, the viscosity of liquid water at $1 \mathrm{bar}, 25^{\circ} \mathrm{C}$ is approximately $1 \times 10^{-3} \mathrm{~Pa} \mathrm{~s}$, or more than 50 times greater than the highest viscosity shown in Figure 2.3.

Figure 2.4 shows the solubility of $\mathrm{CO}_{2}$ and nitrogen $\left(\mathrm{N}_{2}\right)$ in water, where $\mathrm{N}_{2}$ is chosen as a proxy for air, as a function of gas composition (mole fraction) for three different temperatures (Spycher et al., 2003). As shown, $\mathrm{CO}_{2}$ is much more soluble in water than $\mathrm{N}_{2}$ (air), and solubility decreases as temperature increases. Carbon dioxide solubility also decreases as pressure decreases, an effect that can lead to the formation of $\mathrm{CO}_{2}$ gas bubbles when $\mathrm{CO}_{2}$-saturated ground water migrates upwards in the subsurface. As a rule of thumb, $\mathrm{CO}_{2}$ solubility in water is approximately 50 times larger than that of air. 
In addition to density, viscosity, and solubility, the transport of $\mathrm{CO}_{2}$, especially in the shallow subsurface, is controlled by molecular diffusivity. The molecular diffusivity of $\mathrm{CO}_{2}$ in air is comparable to that of other components in air (e.g., $\mathrm{N}_{2}, \mathrm{O}_{2}, \mathrm{H}_{2} \mathrm{O}$ ) and is approximately $1.65 \times 10^{-}$ ${ }^{5} \mathrm{~m}^{2} \mathrm{~s}^{-1}$ at $25^{\circ} \mathrm{C}, 1$ bar (Vargaftik et al., 1996). As pressure increases with depth, $\mathrm{CO}_{2}$ becomes denser and molecular diffusivity decreases. As with solubility, pressure and temperature have compensating effects on molecular diffusion; increasing pressure tends to decrease diffusivity while increasing temperature increases it.

In summary, $\mathrm{CO}_{2}$ is a dense and inviscid gas relative to air. Thus $\mathrm{CO}_{2}$ will tend to be mobile and sink due to buoyancy effects. However, because $\mathrm{CO}_{2}$ and other gases in the near surface are fully miscible, no significant density segregation is expected to occur in gas mixtures unless there is relative flow between gas and liquid water. This flow may cause more soluble $\mathrm{CO}_{2}$ to preferentially dissolve in groundwater and leave behind a gas mixture enriched in the less soluble components. If groundwater pressure decreases or temperature increases, exsolution and bubbling may occur to release $\mathrm{CO}_{2}$ back to the gas phase.

\section{CONTROLS ON THE CO $\mathrm{CO}_{2}$ LEAKAGE OR SEEPAGE SIGNAL (LOSS)}

\subsection{Introduction}

In this section we summarize numerical simulation results of the leakage and seepage of $\mathrm{CO}_{2}$ from geologic $\mathrm{CO}_{2}$ storage sites. The simulation results are based on simple conceptualizations of the subsurface and atmospheric surface layer (hereafter referred to as surface layer) and include the effects of multiphase (gas and liquid) flow and multicomponent (air, $\mathrm{CO}_{2}$, and $\mathrm{H}_{2} \mathrm{O}$ ) transport, while neglecting ecological and geochemical processes. The purpose of summarizing these results is to provide a context for the later discussions of the sources and variability of natural background $\mathrm{CO}_{2}$ and monitoring strategies to detect LOSS. The simulations are carried out using a newly developed module of TOUGH2 (Pruess et al., 1999) called T2CA about which further details can be found in Oldenburg and Unger $(2003 ; 2004)$.

\subsection{Simulation Results}

\subsubsection{Subsurface}

The system we consider consists of a thick $(30 \mathrm{~m})$ unsaturated zone into which a $\mathrm{CO}_{2}$ leakage flux is injected from below. The leakage fluxes are arbitrarily set by prescribing annual losses of $0.1 \%, 0.01 \%$, and $0.001 \%$ by mass of a $4 \times 10^{9} \mathrm{~kg} \mathrm{CO}_{2}$ storage reservoir corresponding to fluxes of $4.04 \times 10^{-8}, 4.04 \times 10^{-7}$, and $4.04 \times 10^{-6} \mathrm{~kg} \mathrm{~m}^{-2} \mathrm{~s}^{-1}$ if the leakage occurs over a $100 \mathrm{~m}$ radius region. For reference, a leakage rate of $0.01 \% \mathrm{yr}^{-1}$ would meet atmospheric stabilization targets, whereas a leakage rate of $0.1 \% \mathrm{yr}^{-1}$ may serve as an upper limit for environmental tolerance because it is still effective for some energy and population scenarios (Hepple and Benson, 2002). The leakage area was one of the many properties of the system that was varied as part of the 
sensitivity analysis discussed below. Rainfall infiltration flows downward through the section and acts to dissolve $\mathrm{CO}_{2}$ and transport it downward. Additional properties of the system are provided in Table 3.1 .

Figure 3.1 shows the steady-state simulation results for the base case at the three different leakage rates. Carbon dioxide concentrations in the shallow subsurface increase with increasing leakage rate, as diffusion and rainfall infiltration are overwhelmed by larger leakage fluxes. Note further the limited degree to which the $\mathrm{CO}_{2}$ spreads outward in the vadose zone despite the density contrast. Pressure gradients induced by the active leakage flux dominate over gravity effects here and thus lead to vertical $\mathrm{CO}_{2}$ flow through the vadose zone to the ground surface.

Figure 3.2 shows plots of seepage flux and near-surface $\mathrm{CO}_{2}$ concentration (mole fraction) summarizing a large number of simulations carried out as part of a sensitivity analysis (Oldenburg and Unger, 2003). For reference, we have plotted a typical ecosystem efflux of $\mathrm{CO}_{2}$ of $4.4 \times 10^{-7}$ $\mathrm{kg} \mathrm{m}^{-2} \mathrm{~s}^{-1}$ (Baldocchi and Wilson, 2001) and the soil-gas $\mathrm{CO}_{2}$ mole fraction $\left(x_{\text {gas }}{ }^{\mathrm{CO} 2}=0.3\right)$ that has caused tree mortality by root suffocation (Farrar et al., 1995). As shown, the leakage flux exerts the strongest control on flux and concentration at the ground surface. Permeability and permeability anisotropy are also very important in controlling $\mathrm{CO}_{2}$ seepage flux and near-surface concentrations. The fundamental observation from these simulations is that subsurface $\mathrm{CO}_{2}$ concentrations from leakage and seepage can be high in the near-surface environment, even when the fluxes are of the same order of magnitude as the ecosystem efflux.

\subsubsection{Surface Layer}

We have also applied the new simulation capability to the coupled subsurface-surface layer system. This approach involves the assumption of a logarithmic wind profile (e.g., Slade, 1968) that is constant and not affected by $\mathrm{CO}_{2}$ seepage. This approximation appears to be well satisfied for seepage fluxes up to approximately $10^{-4} \mathrm{~kg} \mathrm{~m}^{-2} \mathrm{~s}^{-1}$ and wind speeds greater than $1 \mathrm{~m}$ $\mathrm{s}^{-1}$ (Britter, 1989; Oldenburg and Unger, 2003; 2004). We present in Figure 3.3 simulation results showing subsurface and surface layer $\mathrm{CO}_{2}$ concentrations (mass fraction) and gas-phase velocity vectors for the cases of winds of 1,3 , and $5 \mathrm{~m} \mathrm{~s}^{-1}$ at a height of $10 \mathrm{~m}$ from the ground surface and neutral atmospheric conditions. Other properties of the system are listed in Table 3.2 and further details can be found in Oldenburg and Unger (2004). Note the mass fraction scale in Figure 3.3 shows that $\mathrm{CO}_{2}$ concentrations in the surface layer are very low, barely above the background concentration of $370 \mathrm{ppmv}$ which would be 0.00056 by mass fraction. The fundamental conclusion is that surface winds and atmospheric dispersion are very effective at diluting $\mathrm{CO}_{2}$ seepage fluxes. However, stagnant conditions and topographic depressions are moderating effects that can allow larger $\mathrm{CO}_{2}$ concentrations to develop.

\section{CONTROLS ON BACKGROUND FLUXES AND CONCENTRATIONS}

\subsection{Introduction}

In this section, we define "background" $\mathrm{CO}_{2}$ as $\mathrm{CO}_{2}$ derived primarily from the atmosphere and biologically mediated oxidation of organic carbon (respiration). We will not include in this 
discussion $\mathrm{CO}_{2}$ derived from high heat flow environments (e.g., volcanic-hydrothermal, metamorphic) or from leaking natural fossil hydrocarbon reservoirs. Background soil $\mathrm{CO}_{2}$ fluxes and concentrations are dependent on $\mathrm{CO}_{2}$ production in the soil, movement of $\mathrm{CO}_{2}$ from sub-soil sources into the soil column, and exchange of $\mathrm{CO}_{2}$ with the atmosphere by concentration and pressure-driven transport processes. A diagram of soil $\mathrm{CO}_{2}$ sources and interchanges is shown in Figure 4.1, which shows exchange with the atmosphere, production from decay of organic matter such as leaf litter, uptake by plants, production by root respiration, deep degassing, release from groundwater due to depressurization, and production by oxidation of organic carbon in groundwater at the water table.

\section{2 $\mathrm{CO}_{2}$ Production in Soil}

Biologically produced $\mathrm{CO}_{2}$ in soils is derived from root respiration and decay of organic matter (aerobic microbial respiration). The rate of root respiration is related to the plant vitality (e.g., Mogensen, 1977). Although litter and root exudates provide the source of carbon for decomposition processes, the rate of decomposition and associated $\mathrm{CO}_{2}$ production is largely dependent on soil temperature and moisture, soil aeration, substrate quality, and $\mathrm{pH}$ (e.g., Wiant, 1967a; Wiant 1967b; Edwards, 1975; Singh and Gupta, 1977; Amundson et al., 1989; Wood et al., 1993). Both diurnal and seasonal temperature changes have been shown to affect strongly the rate of $\mathrm{CO}_{2}$ production (by both root respiration and decay processes), and related concentrations and fluxes, with production in the soil increasing with temperature (e.g., Parada et al., 1983; Amundson and Smith, 1988; Osozawa and Hasegawa, 1995). Also, at soil water contents between the permanent wilting point and $60-80 \%$ saturation, increasing water content increases the rates of soil $\mathrm{CO}_{2}$ production (Alexander, 1977), whereas at higher or lower moisture contents, production rates may decrease (Kucera and Kirkham, 1971). Figure 4.2 shows vertical profiles of repeated measurements of soil $\mathrm{CO}_{2}$ concentration at one site in central California and demonstrates how $\mathrm{CO}_{2}$ concentration can vary over time due to changes in soil temperature and water content (Lewicki et al., 2003a).

\section{3 $\mathrm{CO}_{2}$ from Deep Sources}

Carbon dioxide may also enter soils from sub-soil sources. A number of studies have observed that $\mathrm{CO}_{2}$ concentrations can increase with depth down to the water table (e.g., Wood and Petraitis, 1984; Keller, 1991; Keller and Bacon, 1998). This can occur by groundwater degassing of $\mathrm{CO}_{2}$ derived from respiration or atmospheric $\mathrm{CO}_{2}$ that was dissolved in infiltration moving through the vadose zone. Recharging groundwater can also introduce particulate organic carbon that is subsequently oxidized to $\mathrm{CO}_{2}$ by microbes under aerobic conditions (e.g., Wood and Petraitis, 1984). Figure 4.3 shows vertical $\mathrm{CO}_{2}$ concentration profiles resulting from this process. In addition, where soil parent material contains ancient organic carbon, oxidation of this carbon in the vadose zone can be a source of $\mathrm{CO}_{2}$ (e.g., Keller and Bacon, 1998). Carbon dioxide from any of these sources may then be transported upwards into the soil column. 


\subsection{Exchange of $\mathrm{CO}_{2}$ with the Atmosphere}

Exchange of soil $\mathrm{CO}_{2}$ with the atmosphere can occur by concentration-gradient-driven flow (diffusion) and by total pressure-gradient-driven flow (advection). Diffusive flow depends on the gas production rate and soil temperature, water content, and properties such as porosity. Advective flow can be driven by (1) atmospheric pressure effects whereby increase and decrease in atmospheric pressure can cause "pumping" of gas into and out of the soil, respectively (e.g., Massmann and Farrier, 1992), (2) wind effects whereby changes in wind speed may induce gas flow through the soil (e.g., Reimer, 1980; Schery et al., 1984; Lewicki et al., 2003a), (3) temperature effects whereby changes in temperature may cause expansion or contraction of soil gas (e.g., Hinkle, 1994), and (4) rainfall. Following precipitation events, rainwater can displace gas and "flush" $\mathrm{CO}_{2}$ from the soil, yielding a temporary increase in soil $\mathrm{CO}_{2}$ flux. Over time, precipitation may also have a "capping" effect, slowing transport of $\mathrm{CO}_{2}$ to the atmosphere and leading to rise of soil $\mathrm{CO}_{2}$ concentrations (e.g., Hinkle, 1994).

\section{REVIEW OF NEAR-SURFACE $\mathrm{CO}_{2}$ MONITORING TECHNOLOGIES}

\subsection{Introduction}

A broad range of methods is currently available to measure $\mathrm{CO}_{2}$ concentrations in the soil, subsoil, and the atmospheric surface layer, carbon isotopic compositions in the soil and sub-soil, and surface $\mathrm{CO}_{2}$ fluxes. These methods have the potential to detect $\mathrm{CO}_{2}$ LOSS. However, they are effective on different spatial and temporal scales, will be able to detect anomalous $\mathrm{CO}_{2}$ at different levels above the background, and differ largely in cost. While excellent comprehensive summaries of available technologies have been presented elsewhere (e.g, Shuler and Tang, 2002), here we briefly summarize the established approaches and expand the list to include some unconventional potential approaches.

\subsection{Conventional $\mathrm{CO}_{2}$ Monitoring Technologies}

\subsubsection{Infrared Gas Analyzer (IRGA)}

The infrared gas analyzer (IRGA) is a device commonly used to measure $\mathrm{CO}_{2}$ concentration in subsurface or atmospheric air. The measurement is based on light absorption in the near infrared part of the spectrum, typically at $4.26 \mu \mathrm{m}$. Portable IRGAs are made for use in the field and require only one person for transport and operation. Instrument set up and calibration typically require less than one hour. IRGAs can be used to make point measurements, an array of measurements, or continuous measurements. Sampling frequency is generally 1-10 Hz. The detection range is variable, typically equal to $0-3000 \mathrm{ppmv}$, although IRGAs are available to measure gases that contain up to $100 \% \mathrm{CO}_{2}$. The precision of IRGAs is as good as $\pm 0.2 \mathrm{ppm}$ at $350 \mathrm{ppm}$ (near atmospheric concentration). The cost of equipment can be relatively inexpensive with capital costs as low as $\$ 500$, but a standard range would be $\$ 5,000-\$ 30,000$. Time and operating costs associated with IRGAs, including a power supply, labor for setup, maintenance and repair, and periodic data retrieval are minimal. 
IRGAs are proven and reliable devices, reasonably priced, and readily transportable. Consequently, they have been used in a broad range of studies including monitoring atmospheric $\mathrm{CO}_{2}$ concentration, occupational health and safety monitoring, pipeline leak detection, ecosystem measurements, volcanic efflux research, micrometeorological research, crop respiration measurements, and human physiology studies. Although IRGAs make point measurements of concentrations, they can be coupled with additional instrumentation to measure surface $\mathrm{CO}_{2}$ fluxes over small (accumulation chamber) to large (eddy covariance) areas (see below). Details of the products and descriptions of their use in research can be found in the following references: LiCOR (2003); Oskarsson et al. (1999); Shuler and Tang (2002); Sorey et al. (1996); and USGS (2000a, 2000b).

\subsubsection{Accumulation Chamber (AC)}

The accumulation chamber (AC) method of soil $\mathrm{CO}_{2}$ flux measurement involves the placement of an open-bottomed $\mathrm{AC}$ directly on the soil surface or on a collar installed on the ground surface and measurement of the rate of soil $\mathrm{CO}_{2}$ accumulation in the $\mathrm{AC}$ by an IRGA (Figure 5.1). As the contained air is circulated through the $\mathrm{AC}$ and the IRGA, $\mathrm{CO}_{2}$ concentration is measured and recorded (e.g., every $1 \mathrm{~s}$ ). To ensure that the gradient in $\mathrm{CO}_{2}$ concentration at the soil-air interface is relatively undisturbed during the measurement, $\mathrm{CO}_{2}$ can be scrubbed from the AC to below-ambient concentrations, and then allowed to rise (e.g., Norman et al., 1992). The rate of change of $\mathrm{CO}_{2}$ concentration in the $\mathrm{AC}(d[\mathrm{CO} 2] / d \mathrm{t})$ is then measured at the point when $\mathrm{CO}_{2}$ concentration equals ambient $\mathrm{CO}_{2}$ concentration. The flux of $\mathrm{CO}_{2}(F)$ is calculated according to

$$
F=\left(\frac{\rho V}{A}\right)\left(\frac{d\left[C O_{2}\right]}{d t}\right)
$$

where $\rho$ is the molar density of air, $V$ is the volume of the system, and $A$ is the area of the AC footprint. The accuracy and precision of the AC method have been estimated at $-12.5 \%$ (Evans et al., 2002) and $\pm 10 \%$ (Chiodini et al., 1998). Portable AC instrumentation requires one person to operate and a single flux measurement can be made within several minutes. The cost of the AC instrumentation, including the IRGA, is typically $\$ 10,000$ to $\$ 15,000$.

Because the AC flux measurement is on the $\mathrm{cm}^{2}$ scale, it can be regarded as a point measurement. Numerous measurements must therefore be made to characterize the spatial trends and variability of fluxes within a study area. Where densely and evenly spaced AC measurements are made along grids, an estimate of the total $\mathrm{CO}_{2}$ emission rate from an area can be made directly. In the case where measured fluxes are unevenly and/or widely spaced, interpolation methods (e.g., Kriging) are used to estimate the total $\mathrm{CO}_{2}$ emission rate from the area. Due to the pointmeasurement nature of the $\mathrm{AC}$ method, it can be difficult to evaluate the temporal variability of soil $\mathrm{CO}_{2}$ fluxes that is typical for an area of interest and the influence of atmospheric parameters (temperature, pressure, wind, precipitation) on this variability. Researchers are often limited to installation of automated $\mathrm{CO}_{2}$ flux measurement stations where single or multiple chambers measure flux repeatedly over time (e.g., Gouldin and Crill, 1997; Rogie et al., 2001; Lewicki et al., 2003a; Edwards and Riggs, 2003). The AC method has been applied in a broad range of studies, 
from volcanic-geothermal gas emission surveys (e.g., Farrar et al., 1995; Chiodini et al., 2001; Salazar et al., 2001; Lewicki et al., 2003b) where relatively high magnitude fluxes (up to $5.8 \times 10^{-4}$ $\mathrm{kg} \mathrm{m}^{-2} \mathrm{~s}^{-1}$ ) are present, to ecological studies (e.g., Rolston, 1986; Mosier, 1989; Norman et al., 1992, Gouldin et al., 1996) where relatively small magnitude $\mathrm{CO}_{2}$ fluxes on the order of $4.6 \times 10^{-7}$ $\mathrm{kg} \mathrm{m}^{-2} \mathrm{~s}^{-1}$ are typical.

\subsubsection{Eddy Covariance (EC)}

Eddy covariance (EC), also known as eddy correlation, is a technique whereby atmospheric $\mathrm{CO}_{2}$ concentrations at a specific height $(z)$ above the ground are measured by an IRGA and these data are integrated with a number of micrometeorological variables including wind velocity, relative humidity, and temperature. These measurements provide a gross conservation of energy and mass over an area of land (the footprint) from which the net $\mathrm{CO}_{2}$ flux can be derived. The principles of measurement begin with the conservation of mass in a system defined by the rate of change of the mixing ratio of $\mathrm{CO}_{2}$ versus the flux of $\mathrm{CO}_{2}$ in three dimensions, plus a biological source or sink term. The equations and algorithms used to construct the $\mathrm{EC}^{-O_{2}}$ flux estimate are under constant development and improvement. The essence of the method involves timeaveraging the product of the time series of fluctuating $\mathrm{CO}_{2}$ concentration $(c(x, y, z, t))$, and the time series of fluctuating vertical wind velocity $(w(x, y, z, t))$. Under steady-state conditions and for sufficiently long averaging time (typically 30 minutes to several hours), this converges to the ensemble mean flux, the average of the product of $w$ and $c$. The measured vertical $\mathrm{CO}_{2}$ flux is an integral of the surface flux over the upwind "footprint." The size of this footprint (typically $\mathrm{m}^{2}$ to $\mathrm{km}^{2}$ ) is primarily related to the measurement height and meteorological conditions. EC measurement stations can be stationary or field-mobile towers, with the mobile setup requiring two or three people and roughly half of a day to install. A sketch of an EC station is shown in Figure 5.2.

A limitation of the EC method is that the measurement assumes a horizontal and homogeneous surface. Varying density of plant cover, land use, and topography are several obvious violations of this assumption that can introduce significant error into the measurement. In general, measurements must be made over terrain with less than 8 to $15 \%$ slope (Baldocchi et al., 1988). Also, if surface heterogeneity can be organized into regions of uniform surface conditions or occurs on a small scale and is randomly distributed, measurement error can be reduced (e.g., Lenschow, 1995). Typical ecological $\mathrm{CO}_{2}$ fluxes in nature are $4.4 \times 10^{-7} \mathrm{~kg} \mathrm{~m}^{-2} \mathrm{~s}^{-1}(10 \mu \mathrm{mol} \mathrm{m}$ $\left.\mathrm{s}^{-1}\right)$ efflux to $1.3 \times 10^{-6} \mathrm{~kg} \mathrm{~m}^{-2} \mathrm{~s}^{-1}\left(30 \mu \mathrm{mol} \mathrm{m} \mathrm{s}^{-2}\right)$ uptake. The absolute range and minimum resolvable flux for $\mathrm{EC}$ have not been documented in the literature. Resolution of the EC method can be as good as $4.4 \times 10^{-9} \mathrm{~kg} \mathrm{~m}^{-2} \mathrm{~s}^{-1}\left(0.1 \mu \mathrm{mol} \mathrm{m} \mathrm{m}^{-2} \mathrm{~s}^{-1}\right)$ under favorable meteorologic and terrain conditions. Estimates of the precision of EC vary widely from \pm 5 to $30 \%$. Short-term error has been estimated to be $\pm 7 \%$ during the daytime and $\pm 12 \%$ during the nighttime; long-term error is on the order of $\pm 5 \%$.

The capital cost for EC equipment could be as low as $\$ 5000$ per station including a small stand or tower, but the typical range would be $\$ 15,000-\$ 40,000$, depending on tower size and meteorological instrumentation. The operating costs are primarily the power supply, labor, and time for a survey. The main advantage of $\mathrm{EC}$ is that it integrates $\mathrm{CO}_{2}$ flux over large areas and 
therefore could be an inexpensive monitoring strategy. The greatest disadvantage is that EC is prone to significant error depending upon the meteorological and terrain conditions at the study site. As a result, it typically cannot provide temporally and spatially continuous measurements. Rather, gaps in time and space must be tolerated. EC has primarily been applied in meteorological, ecological, and terrestrial carbon cycle investigations. For detailed information on the theory of eddy flux correlation and its applications, readers are referred to Anderson and Farrar (2001), Baldocchi (2003), Baldocchi and Myers (1998), Baldocchi et al. (1996), Baldocchi et al. (2001), Baldocchi and Wilson (2001), Foken and Wichura (1996), Gouldin et al. (1996), LiCor (2003), Massman and Lee (2002), and the USGS (2000a, b).

\subsubsection{Light Detection and Range Finding (LIDAR)}

The method of light detection and ranging (LIDAR) is the optical analog of radar, using laser radiation to probe the atmosphere, and can be used to measure trace atmospheric gases (e.g., $\mathrm{NO}_{2}, \mathrm{SO}_{2}, \mathrm{O}_{3}, \mathrm{H}_{2} \mathrm{O}, \mathrm{CH}_{4}, \mathrm{CO}_{2}$ ). While there are a range of LIDAR techniques in use, atmospheric $\mathrm{CO}_{2}$ can be measured by two LIDAR methods: (1) Raman LIDAR, and (2) differential absorption LIDAR (DIAL).

The Raman LIDAR method involves transmitting laser light into the atmosphere and then detecting the laser radiation that has been shifted in wavelength due to interaction with the target scattering molecules along the resolved path length. Raman scattering thus provides wavelength shifts that are distinct for the target molecules (e.g., $\mathrm{CO}_{2}$ ), according to the vibrational energy states of the molecules. In the case of $\mathrm{CO}_{2}$, the backscattered power of the wavelength-shifted signal is proportional to the $\mathrm{CO}_{2}$ concentration. By comparing the Raman signal of the $\mathrm{CO}_{2}$ to the Raman signal of $\mathrm{N}_{2}$ or $\mathrm{O}_{2}$, a direct measurement of $\mathrm{CO}_{2}$ concentration can be obtained.

The DIAL technique involves using a tunable laser at two wavelengths to estimate the concentration of a target-absorbing species (e.g., $\mathrm{CO}_{2}$ ). In the case of $\mathrm{CO}_{2}$, one wavelength is selected to coincide with the center of a $\mathrm{CO}_{2}$ absorption line and the second wavelength is selected to fall in a nearby non-absorbing region. Laser power at both wavelengths is transmitted either sequentially or simultaneously over the same path in the atmosphere and is elastically scattered into the field of view of the LIDAR receiver. The average $\mathrm{CO}_{2}$ concentration over the path length can be determined from the ratio of the backscatter signals for the two laser wavelengths.

Raman LIDAR and DIAL can be truck- or plane-mounted. Truck-based measurements (see sketch in Figure 5.3) can cover up to tens of $\mathrm{km}^{2}$ per day; plane-mounted systems can potentially cover tens to hundreds of $\mathrm{km}^{2}$ during a given survey. The detection range depends upon the wavelength and strength of absorption and typically ranges from $<1$ ppmv to several percent for $\mathrm{CO}_{2}$. The precision for truck mounted or airborne measurements is generally from $1 \%$ to $5 \%$ of maximum range; from 3.4 to $27 \mathrm{ppm}$ at $1 \mathrm{~km}$ path length and from 14 to $86 \mathrm{ppm}$ at $2 \mathrm{~km}$ path length at $330 \mathrm{ppm}$ in clean air. The cost of these surveying techniques ranges from hundreds of dollars for a truck-mounted survey to thousands of dollars for an airborne survey. The advantages of Raman LIDAR and DIAL are that these are rapidly developing technologies with potential applications over multiple spatial scales. The main disadvantages are that they are 
expensive and measure average concentration over a path length, which means that a large localized perturbation cannot be distinguished from a small change in the bulk mean concentration. For more in-depth discussion of these techniques, the reader is referred to Schlessinger (1995), Radziemski et al. (1987), Shuler and Tang (2002); Jet Propulsion Laboratory, National Aeronautics and Space Administration, http://lidar.jpl.nasa.gov/, http://asdwww.larc.nasa.gov/lidar/lidar.html.

\subsection{Unconventional $\mathrm{CO}_{2}$ Monitoring Technologies}

The need for affordable and precise monitoring of gas fluxes and concentrations in the nearsurface environment for an array of applications including pipeline leak detection, land mine detection, ecological studies, and geologic $\mathrm{CO}_{2}$ storage verification has produced a variety of novel monitoring approaches. While the approaches discussed below are not proven nor in wide use, we felt they deserve mention and serve to demonstrate that near-surface gas monitoring is a wide-open area for innovation and development.

\subsubsection{Hyperspectral Imaging of Vegetative Stress}

Hyperspectral imaging measures the absorption of specific wavelengths of light from visible through infrared by material exposed on the surface of the Earth. Hyperspectral imaging is based on principles similar to infrared absorption by $\mathrm{CO}_{2}$; however, in the case of hyperspectral imaging, images covering many narrow, contiguous wavelength bands are simultaneously collected. A spectral response indicative of the exposed material on the Earth's surface is then extracted from each pixel in the image. Because the absorption features in the spectra are determined by the chemical composition and physical structure of surface materials, they can be used to identify these materials. Hyperspectral data have been used in a wide range of studies, including mineral exploration, vegetation communities or species mapping, hazardous material remediation, ecosystem monitoring, and agricultural problems. One important potential application of hyperspectral imaging to monitoring for $\mathrm{CO}_{2}$ leakage is the detection of changes in plant health and communities related to elevated soil $\mathrm{CO}_{2}$ concentration (e.g., Martini et al., 2000).

The spectroradiometers used to make the measurements can be portable, truck-mounted, planemounted, or satellite-based and related survey areas vary from sub- $\mathrm{m}^{2}$ to continental scale. Although individual measurements are rapid, the time required for data analysis may range from days to weeks. The detection range is variable and depends upon the signal to noise ratio of acquired data and the strength of the spectral signature. Hyperspectral imaging can reconstruct net energy exchange, net primary production, or gross primary production with $20 \%$ error or less. The cost varies by orders of magnitude depending upon the platform for deployment; airborne and satellite instrumentation costs range from hundreds of thousands to millions of dollars. The main advantage of hyperspectral imaging is the potential for remote sensing of $\mathrm{CO}_{2}$ leakage by proxy over large land areas. Two clear disadvantages of the method are the cost and that it is still under development. For further information on hyperspectral imaging, interested readers are referred to the following websites: http://aviris.jpl.nasa.gov/ (JPL AVIRIS), www.earthsearch.com (Earth Search Sciences, Inc.), www.es.ucsc.edu/ hyperwww/, 
(Hyperspectral Imaging Project), www.geo.mtu.edu/ anpilant/rsi/rsi hyperspectral/index.html (Michigan Technical University Remote Sensing and Ecosystem Sensing Institute) and www.phy.mtu.edu/facilities/hyperspectral.html (MTU physics department's hyperspectral imaging laboratory), www.ultraspectral.com, www.techexpo.com/WWW/optoknowledge/IS resources.html.

\subsubsection{Long Open Path IR and Tunable Lasers}

Long open path IR and tunable lasers measure cumulative $\mathrm{CO}_{2}$ concentration along a given path length based on infrared absorption at 4.26, 2.78, 2.00, or $1.57 \mu \mathrm{m}$ wavelengths. While still under development, these techniques hold great promise for ground-level $\mathrm{CO}_{2}$ concentration measurements. Such technology uses a fixed laser with a tunable filter, one or more retroreflectors, and a detector. The laser sends pulses to one or more reflectors within the study area and the signal is returned to a detector at the beginning of the light path. The measured infrared absorption reflects the cumulative $\mathrm{CO}_{2}$ over the path length. Each instrument thus has the potential to provide continuous monitoring of atmospheric surface layer $\mathrm{CO}_{2}$ over several $\mathrm{km}^{2}$. The detection range is from less than 1 ppmv to several percent $\mathrm{CO}_{2}$ and measurement precision is expected to be $\pm 3 \%$ or better. Although these instruments are not yet developed to the point of commercial viability, the costs are projected to be thousands of dollars per unit. The primary advantage of long open path IR and tunable laser technology is the potential to cover a large area with automated, continuous measurement, and the main disadvantage is that it is still under development. Shuler and Tang (2002) and Duarte (1995) provide further information.

\subsubsection{Micro-Electronic Mechanical Systems (MEMS), Smart Dust, Motes}

Micro-electronic mechanical systems (MEMS), Smart Dust, and Motes are miniaturized $\left(\mathrm{mm}^{3}-\mathrm{cm}^{3}\right.$ scale) sensing and communications platforms with the potential to measure absorption of IR radiation at $\mathrm{CO}_{2}$-specific wavelengths. These technologies have the potential to measure $\mathrm{CO}_{2}$ concentrations in the atmospheric surface layer and the subsurface. MEMS, Smart Dust, and Motes are currently under development; therefore, the time and length scales and the sensitivity and precision of the $\mathrm{CO}_{2}$ concentration measurements are uncertain. The promising concept for these miniature devices is that they could be widely dispersed and autonomous, each broadcasting its $\mathrm{CO}_{2}$ concentration measurements a short distance to the next device, and the whole set of instruments forming a network to deliver widely dispersed data to a single recording location. Smart Dust is particularly attractive because it is small, inexpensively fabricated in mass quantities, could be easily scattered around a given area, and self-assembles into a network so that data collection and coverage are simplified. The primary advantages of these methods are the small size, potentially low cost, and wide coverage of the measurements. The main disadvantage is that the technology is still under development. For more information on MEMS, Smart Dust, and Motes technologies, refer to http://www.ion-optics.com/.

\subsubsection{Animal Detectors}

Dogs are currently used for scent tracking in search and rescue operations and detection of illicit drugs, bombs, and landmines. Other animals such as insects may be useful for $\mathrm{CO}_{2}$ detection. 
For example, mosquitoes find and target animals by tracing their exhaled $\mathrm{CO}_{2}$ plumes. The potential use of animals to detect elevated atmospheric $\mathrm{CO}_{2}$ concentrations related to $\mathrm{CO}_{2}$ leakage would be based on the highly refined detection of $\mathrm{CO}_{2}$ by the animal's olfactory system coupled with intensive training. Animals could cover from hundreds of square meters to a square kilometer per day of surveying. The sensitivity and precision of these animals' ability to detect $\mathrm{CO}_{2}$ remains uncertain, but dogs trained to find landmines have been able detect as low as one molecule of explosive material per breath (Webb and Phelan, 2002). The training of dogs for present scent-based detection roles costs thousands of dollars per dog and special handling and care are needed. The cost of training insects, if it is shown that they are useful, would likely be high also. The greatest advantage of this potential approach is the extraordinary sensitivity of biological olfactory systems. The main disadvantage is that the techniques have not yet been demonstrated; no dogs have been trained to detect $\mathrm{CO}_{2}$ or indicate $\mathrm{CO}_{2}$ concentrations, nor has a system for $\mathrm{CO}_{2}$ detection using insects been developed. Furthermore, the natural variability of $\mathrm{CO}_{2}$ concentration complicates LOSS detection by animals, and diminishes the advantages of sensitivity of animal olfactory systems applied to sensing $\mathrm{CO}_{2}$.

\section{STRATEGIES FOR $\mathrm{CO}_{2}$ STORAGE VERIFICATION}

\subsection{Introduction}

As the previous section shows, technologies for detecting $\mathrm{CO}_{2}$ concentrations and fluxes are well established and there are rapid developments being made that will extend the capabilities and potentially lower the cost of $\mathrm{CO}_{2}$ monitoring. However, there is a wide gap between the performance capabilities of technological devices and their applicability for geologic carbon sequestration verification. The fundamental challenge for verification when leakage and seepage fluxes are very small is discerning the leakage signal from background variability. In most cases, $\mathrm{CO}_{2}$ LOSS will be non-existent because no seepage will occur. Therefore, monitoring at $\mathrm{CO}_{2}$ storage sites will typically record background natural variability of the ecological system. To meet the challenge of $\mathrm{CO}_{2}$ storage verification, sophisticated procedures or new technologies may have to be developed. In this section, we discuss some potential ways that the $\mathrm{CO}_{2} \mathrm{LOSS}$ could be discerned and quantified from measurements made in the near-surface environment with existing conventional devices.

\subsection{Sub-Surface Gas Geochemistry}

Subsurface gases are less affected by surface environmental parameters than are gases above the ground surface. Therefore, monitoring for leakage from geologic carbon sequestration reservoirs should be focused on the subsurface. Both the carbon isotopic composition of $\mathrm{CO}_{2}$ and bulk gas chemistry can be used to determine the origin of $\mathrm{CO}_{2}$ and thereby potentially detect leakage from the fossil-fuel derived $\mathrm{CO}_{2}$ present in a $\mathrm{CO}_{2}$ storage reservoir. 


\subsubsection{Carbon Isotopes}

Carbon isotopic compositions of vadose zone $\mathrm{CO}_{2}$ reflect the compositions and relative proportions of the contributing sources and may be used as tracers of the origin of $\mathrm{CO}_{2}$. In the following discussion, carbon-13 values will be reported as $\delta^{13} \mathrm{C}$, the deviation in parts per thousand (\%) of the ${ }^{13} \mathrm{C} /{ }^{12} \mathrm{C}$ ratio in the sample from that of the Pee Dee Belemnite (PDB) reference standard. Carbon-14 values will be reported as $\Delta^{14} \mathrm{C}$, the deviation, in parts per thousand of the ${ }^{14} \mathrm{C} /{ }^{12} \mathrm{C}$ ratio in the sample from that of the reference standard (oxalic acid decay corrected to 1950). The instrumentation used in measuring stable isotopes is a lab-based mass spectrometer, while ${ }^{14} \mathrm{C}$ is measured using an accelerator mass spectrometer (AMS). Isotopic analyses are performed on gas samples that have been collected in the field and subsequently prepared using standard geochemical laboratory methods. Some representative costs are $\$ 10-\$ 30$ per sample for ${ }^{13} \mathrm{C}$, and $\$ 200-\$ 600$ per sample for ${ }^{14} \mathrm{C}$.

In the absence of large magnitude flow of $\mathrm{CO}_{2}$ from subsurface source(s) to the atmosphere, the isotopic composition of $\mathrm{CO}_{2}$ in the soil column will be most strongly affected by contributions from root respiration, decay of organic material, and the atmosphere. The $\delta^{13} \mathrm{C}$ and $\Delta^{14} \mathrm{C}$ values of present atmospheric $\mathrm{CO}_{2}$ are close to -7 and $70 \%$, respectively. The $\delta^{13} \mathrm{C}$ composition of $\mathrm{CO}_{2}$ respired from plant roots is isotopically depleted relative to the atmosphere due to isotopic fractionation associated with photosynthesis and will have an isotopic composition similar to that of the plant. This value will largely depend on whether the plant utilizes a $C_{3}$ or $C_{4}$ photosynthetic pathway; $\mathrm{C}_{3}$ plants (e.g., woody shrubs) typically have bulk $\delta^{13} \mathrm{C}$ values of -24 to $-38 \%$ and $\mathrm{C}_{4}$ plants (e.g., grasses that have evolved to conserve water) have values from -6 to $-19 \%$ (O'Leary, 1988). Likewise, the $\delta^{13} \mathrm{C}$ composition of $\mathrm{CO}_{2}$ derived from decay of soil organic material will be similar to that material and will depend largely on the plant type $\left(\mathrm{C}_{3}\right.$ versus $\mathrm{C}_{4}$ ).

The $\Delta^{14} \mathrm{C}$ composition of soil-respired $\mathrm{CO}_{2}$ is most strongly affected by three components, namely (1) root-respired $\mathrm{CO}_{2}$, (2) $\mathrm{CO}_{2}$ produced by decay of organic matter on time scales of less than one year, and (3) $\mathrm{CO}_{2}$ produced by decay of organic matter on several year to decadal time scales (e.g., Trumbore, 2000). The $\Delta^{14} \mathrm{C}$ values of $\mathrm{CO}_{2}$ derived from the first two sources will be similar to that of the present atmosphere, whereas those of $\mathrm{CO}_{2}$ derived from decay of organic matter on decadal time scales may be enriched relative to the atmosphere due to the increase in ${ }^{14} \mathrm{C}$ in soil organic matter related to nuclear weapons testing in the 1960 's. Also, the $\Delta^{14} \mathrm{C}$ values of soil-respired $\mathrm{CO}_{2}$ may vary seasonally, with the highest values observed during the growing season (e.g., Keller and Bacon, 1998; Trumbore, 2000). With the exception of warming or oxidation of frozen or wetland soils, respectively, decay of ancient organic matter with depleted $\Delta^{14} \mathrm{C}$ values contributes relatively little to the decomposition $\mathrm{CO}_{2}$ flux in most soils due to the recalcitrant nature of ancient organic matter or its sorption onto mineral surfaces and associated resistance to breakdown (e.g., Trumbore, 2000).

In most cases, respiration processes predominantly operate in the soil zone (i.e., typically the upper one to two meters of the subsurface) referred to as the solum. For example, Keller and Bacon (1998) showed that in a Canadian pastureland, 98\% of all subsurface respiration occurred 
in the solum. Therefore, the isotopic compositions of $\mathrm{CO}_{2}$ below the soil should be less affected by respiration processes than those in the soil. At sub-soil depths, however, $\mathrm{CO}_{2}$ can be produced to a lesser extent by groundwater degassing of $\mathrm{CO}_{2}$ derived from atmospheric and soilrespired sources; the $\delta^{13} \mathrm{C}$ value of this $\mathrm{CO}_{2}$ will depend on the relative proportions of the $\mathrm{CO}_{2}$ from these sources and may be close to values measured above in the solum. Oxidation of organic matter at depth may also produce $\mathrm{CO}_{2}$. The $\delta^{13} \mathrm{C}$ value of this $\mathrm{CO}_{2}$ will be similar to the source organic mass and may not vary significantly from those for soil-respired $\mathrm{CO}_{2}$. The ${ }^{14} \mathrm{C}$ values of $\mathrm{CO}_{2}$ from these sub-soil sources will depend on factors such as the residence time of dissolved $\mathrm{CO}_{2}$ in the groundwater and the age of the organic matter. For example, oxidation of ancient organic matter such as peat, lignite, or kerogen will produce $\mathrm{CO}_{2}$ that is highly depleted or free of ${ }^{14} \mathrm{C}$.

The stable carbon isotopic signature of carbon in coal is similar to modern land plants and $\delta^{13} \mathrm{C}$ averages $-25 \%$ o (Faure, 1986). The signature of petroleum ranges from -18 to $-34 \%$ and averages $-28 \%$, whereas associated natural gas is more strongly ${ }^{13} \mathrm{C}$ depleted (Faure, 1986). The average $\delta^{13} \mathrm{C}$ value of $\mathrm{CO}_{2}$ derived from burning of fossil fuels is about $-27 \%$ (e.g., Hoefs, 1987). The $\delta^{13} \mathrm{C}$ signature of $\mathrm{CO}_{2}$ derived from burning of fossil fuels will therefore distinguish it from $\mathrm{CO}_{2}$ derived from atmospheric and $\mathrm{C}_{4}$-plant-derived sources; however, it is similar to that of $\mathrm{CO}_{2}$ from $\mathrm{C}_{3}$ plants and therefore alone will be problematic in distinguishing these sources. However, fossil-fuel-derived $\mathrm{CO}_{2}$ is ${ }^{14} \mathrm{C}$-free. Leaking fossil $\mathrm{CO}_{2}$ will therefore have a ${ }^{14} \mathrm{C}$ signal that is distinct from atmospheric and most biogenic respiration sources. In the absence of oxidation of ancient organic matter in soil parent material, this signal should be easily distinguishable from dominant background $\mathrm{CO}_{2}$ sources. For example, focused leakage fluxes of fossil $\mathrm{CO}_{2}$ such as those discussed in Section 3 occurring over a circular region of $100 \mathrm{~m}$ radius (area equal to $3.14 \mathrm{x}$ $10^{4} \mathrm{~m}^{2}$ ) that are $0.001,0.01$, and $0.1 \% \mathrm{yr}^{-1}$ of the initial mass of a $4 \times 10^{9} \mathrm{~kg} \mathrm{CO}_{2}$ reservoir (Oldenburg and Unger, 2003) would be equivalent to $0.92,9.2$, and $92 \mu \mathrm{mol} \mathrm{CO} \mathrm{Cm}^{-2} \mathrm{~s}^{-1}(4.04 \mathrm{x}$ $10^{-8}, 4.04 \times 10^{-7}$, and $4.04 \times 10^{-6} \mathrm{~kg} \mathrm{~m}^{-2} \mathrm{~s}^{-1}$ ), respectively. Given a background soil $\mathrm{CO}_{2}$ respiration rate and $\Delta^{14} \mathrm{C}$ composition typical of a temperate forest (i.e., $1.9 \mu \mathrm{mol} \mathrm{m} \mathrm{m}^{-2} \mathrm{~s}^{-1}$ and 128 $\%$, respectively (Trumbore, 2000)), by mass balance, the $\Delta^{14} \mathrm{C}$ values of soil $\mathrm{CO}_{2}$ samples will be $-240,-807$, and $-977 \%$ for leakage fluxes of $0.92,9.2$, and $92 \mu \mathrm{mol} \mathrm{CO} \mathrm{m}^{-2} \mathrm{~s}^{-1}$, respectively. The differences between these values and the isotopic composition of background soil $\mathrm{CO}_{2}$ are much greater than the precision of the ${ }^{14} \mathrm{C}$ analysis (e.g., \pm 4-8 \%o depending on the laboratory method used (Southon et al., 1993)). These results indicate that leakage fluxes over this range of magnitudes would be detectable by ${ }^{14} \mathrm{C}$ analyses of soil $\mathrm{CO}_{2}$. An order of magnitude lower leakage flux $\left(0.092 \mu \mathrm{mol} \mathrm{CO} \mathrm{CO}^{-2} \mathrm{~s}^{-1}\right)$ would yield a $\Delta^{14} \mathrm{C}$ value of soil $\mathrm{CO}_{2}$ of $76 \%$. This difference is also detectable by the ${ }^{14} \mathrm{C}$ method; however, the ${ }^{14} \mathrm{C}$ composition of the background soil $\mathrm{CO}_{2}$ and its seasonal variability should be well characterized to minimize error of the calculation.

We expect production rates of $\mathrm{CO}_{2}$ from sub-soil sources to be significantly lower than those in the soil column (e.g., Wood and Patraitis, 1984; Keller and Bacon, 1998). Therefore, in the absence of a large source of $\mathrm{CO}_{2}$ derived from respiration of ancient sedimentary organic carbon, 
the range of fluxes of ${ }^{14} \mathrm{C}$-free $\mathrm{CO}_{2}$ from a leaking sequestration reservoir described above should be readily detectable using carbon isotopic analyses of $\mathrm{CO}_{2}$ collected from sub-soil depths.

\subsubsection{Bulk Soil Gas Composition}

While carbon isotopic analyses provide the most definitive information regarding the origin of subsurface $\mathrm{CO}_{2}$, the bulk chemical composition of gases collected at soil and sub-soil depths can also be used to assess whether $\mathrm{CO}_{2}$ is produced at depth and if so, whether it is derived from non-respiration sources. Measurement of $\mathrm{CO}_{2}$ concentration with depth in the vadose zone will provide information about $\mathrm{CO}_{2}$ production; an increase in $\mathrm{CO}_{2}$ concentration below the soil indicates $\mathrm{CO}_{2}$ production at depth. In most cases, production of $\mathrm{CO}_{2}$ by oxidative decay of organic matter will consume $\mathrm{O}_{2}$ at approximately the same rate. In addition, $\mathrm{O}_{2}$ will diffuse down into the soil and sub-soil as subsurface $\mathrm{CO}_{2}$ diffuses to the atmosphere. A leakage flux of fossil $\mathrm{CO}_{2}$ would produce high $\mathrm{CO}_{2}$ concentration at depth, but would not be accompanied by $\mathrm{O}_{2}$ consumption, although $\mathrm{O}_{2}$ would still diffuse down into the soil. As a result, the $\mathrm{CO}_{2}$ concentration and $\mathrm{O}_{2}$ concentration-depth profiles generated should be different in these two cases. Assuming that diffusion is the dominant gas transport process in the absence a $\mathrm{CO}_{2}$ leakage flux, the expected $\mathrm{CO}_{2}$ concentration and $\mathrm{O}_{2}$ concentration-depth profiles resulting from background $\mathrm{CO}_{2}$ respiration and $\mathrm{O}_{2}$ consumption rates could be predicted with diffusion models and compared to measured profiles following deep $\mathrm{CO}_{2}$ injection. Although degassing of respiration and atmospheric-derived $\mathrm{CO}_{2}$ from groundwater may show similar chemical trends to a leakage flux of fossil $\mathrm{CO}_{2}$, subsurface $\mathrm{CO}_{2}$ concentrations associated with degassing and biological respiration processes have generally been reported to be less than $13 \% \mathrm{CO}_{2}$, by volume (e.g., Wood and Petraitis, 1984; Amundson and Davidson, 1990; Wood et al., 1993). Concentrations of $\mathrm{CO}_{2}$ in the near surface associated with leakage fluxes of 9.2 to $92 \mu \mathrm{mol} \mathrm{CO}_{2}$ $\mathrm{m}^{-2} \mathrm{~s}^{-1}$ could be much higher, ranging from $\sim 32-63 \%$ (Oldenburg and Unger, 2003). Importantly, however, the predicted near surface $\mathrm{CO}_{2}$ concentration produced by a leakage flux of $0.92 \mu \mathrm{mol}$ $\mathrm{CO}_{2} \mathrm{~m}^{-2} \mathrm{~s}^{-1}$ may only be $\sim 4 \%$ (Oldenburg and Unger, 2003); this $\mathrm{CO}_{2}$ concentration may be difficult to distinguish from background $\mathrm{CO}_{2}$ concentrations. The background $\mathrm{CO}_{2}$ concentration for the study area and its seasonal variability should be well characterized in order to identify anomalously high $\mathrm{CO}_{2}$ concentrations that may be related to fossil $\mathrm{CO}_{2}$ leakage from geologic $\mathrm{CO}_{2}$ storage sites.

\subsubsection{Measurement Strategies}

Soil gas $\mathrm{CO}_{2}$ concentrations can be rapidly measured at many locations over large areas using a soil probe and a portable infrared gas analyzer (IRGA). This method requires inserting a soil probe to the depth of interest, usually less than $1 \mathrm{~m}$, and measuring $\mathrm{CO}_{2}$ concentrations (typically to $\pm 100 \mathrm{ppmv}$ or $0.01 \%$ ) as the gas is pumped from the soil to the IRGA by an internal pump. Alternatively, a gas sample can be collected from the probe using a syringe and vial. The chemistry of gas samples can then be analyzed in the laboratory using standard gas chromatographic techniques. Each measurement or collection of a gas sample can be conducted within minutes, allowing for many measurements to be made over relatively short periods of time. However, the background $\mathrm{CO}_{2}$ signal would likely be high here, relative to sub-soil depths 
and could make detection of $\mathrm{CO}_{2}$ concentration anomalies related to relatively small leakage fluxes difficult. Background $\mathrm{CO}_{2}$ concentration variability should therefore be well characterized. Subsoil sampling of gases would be valuable to avoid large respiration signals. However, this sampling requires installation of sampling wells or trenches, if these were not previously in place, to install permanent $\mathrm{CO}_{2}$ concentration sensors or provide locations at which to collect gas samples for chemical analyses. These aspects may make implementation of sub-soil gas sampling at numerous locations within a large area impractical.

Numerous statistical methods (e.g., Kriging) can be used to interpolate unevenly or widely spaced $\mathrm{CO}_{2}$ concentration measurements within the study area to an evenly spaced grid. This grid can then be contoured to look for spatial trends in the data. Autocorrelation analysis of the spatial data set involves the calculation of correlation coefficients for the data as a function of separation distance $\left(C_{\Delta X, \Delta Y}\right)$ between the measurements $(z)$ according to

$$
C_{\Delta X, \Delta Y}=\frac{\sum_{i=1}^{m} \sum_{j=1}^{n}\left(z_{(i \cdot \delta X+\Delta X, j \cdot \delta Y+\Delta Y)}-\bar{z}\right)\left(z_{(i \cdot \delta X, j \cdot \delta Y}-\bar{z}\right)}{\left[\sum_{i=1}^{m} \sum_{j=1}^{n}\left(z_{(i \cdot \delta X+\Delta X, j \cdot \delta Y+\Delta Y)}-\bar{z}\right)^{2} \sum_{i=1}^{m} \sum_{j=1}^{n}\left(z_{(i \cdot \delta X, j \cdot \delta Y}-\bar{z}\right)^{2}\right]^{1 / 2}}
$$

where $\Delta X$ and $\Delta Y$ are the separation distances in the horizontal and vertical directions, respectively, $m$ and $n$ and the number of measurements in the horizontal and vertical directions, respectively, and $\delta X$ and $\delta Y$ are the measurement spacing in the horizontal and vertical directions, respectively. Both data contouring and autocorrelation analysis can be used to check for spatial trends in the data that may be related to $\mathrm{CO}_{2}$ leakage. For example, the presence of elevated $\mathrm{CO}_{2}$ concentration together with high degree of spatial autocorrelation of $\mathrm{CO}_{2}$ concentration along a linear trend may indicate $\mathrm{CO}_{2}$ leakage along a linear structure and would require further (e.g., isotopic) evaluation of $\mathrm{CO}_{2}$ sources there.

\subsection{Surface $\mathrm{CO}_{2}$ Concentration and Flux Monitoring}

Carbon dioxide seepage from a storage reservoir may create surface $\mathrm{CO}_{2}$ fluxes and atmospheric surface layer $\mathrm{CO}_{2}$ concentrations of high enough magnitude to distinguish from background $\mathrm{CO}_{2}$. The magnitude of seepage $\mathrm{CO}_{2}$ fluxes and atmospheric $\mathrm{CO}_{2}$ concentrations will depend on a variety of factors such as the style of emission (e.g., focused $\mathrm{CO}_{2}$ flow along a near-surface fault or more diffuse emission through sediments) and wind and density-driven atmospheric dispersion.

Several methods could be used to detect anomalously high atmospheric-surface-layer $\mathrm{CO}_{2}$ concentrations related to seepage. For example, point measurements of $\mathrm{CO}_{2}$ concentration could be made by fixed or portable IRGAs or fixed solid-state sensors. Numerous measurements over a potentially large area would likely be required. In addition, due to the significant atmospheric 
dispersion and dilution of seeping $\mathrm{CO}_{2}$ that is expected under normal wind speed conditions (Oldenburg and Unger, 2003; 2004), anomalous $\mathrm{CO}_{2}$ concentrations may only be a few tens of ppmv above average ambient air $(\sim 370 \mathrm{ppmv})$ downwind from the source. Although the precision of fixed detectors can be \pm 1 ppmv or better, the high cost of the use of many detectors may preclude their use. The use of one or a few portable IRGAs would be significantly lower in cost, but the precision of these are typically no better than $\pm 100 \mathrm{ppmv}$ and it therefore would be problematic to detect low anomalous $\mathrm{CO}_{2}$ concentrations above background variability. Due to the limitations of atmospheric $\mathrm{CO}_{2}$ detection methods, soil and sub-soil $\mathrm{CO}_{2}$ monitoring would likely be a preferred point- $\mathrm{CO}_{2}$ measurement method to detect $\mathrm{CO}_{2}$ related to leakage and seepage.

The EC method may offer a spatially averaged $\mathrm{CO}_{2}$ flux measurement that could be used to detect anomalous $\mathrm{CO}_{2}$ emissions related to seepage. This would require that (1) instrumentation be deployed under the meteorological and terrain conditions necessary to minimize the error of the measurement, (2) the scale of temporal variability (diurnal, seasonal) of background $\mathrm{CO}_{2}$ fluxes be characterized at the study site prior to $\mathrm{CO}_{2}$ injection, and (3) the magnitude of the anomaly can be detected above background variability, given the error of the measurement. In addition, determination of the location of the $\mathrm{CO}_{2}$ flux anomaly and its geometry within the footprint area would require additional point measurements, e.g., accumulation chamber (see below).

The AC method could be used to detect anomalous soil $\mathrm{CO}_{2}$ flux associated with seepage. Because the AC method provides a flux measurement on the $\mathrm{cm}^{2}$ scale, numerous measurements must be made to characterize the spatial trends and variability of fluxes within the study area. However, the AC method offers the benefit over the EC method in that small-scale spatial trends in surface fluxes can be mapped and the location and geometry of areas of anomalous $\mathrm{CO}_{2}$ flux can be delineated, as described above for soil $\mathrm{CO}_{2}$ concentrations. Also, the $\mathrm{AC}$ measurement requires few terrain or atmospheric conditions to be met, making it a more flexible method than EC. Due to the point measurement nature of the AC method, it can be difficult to evaluate the temporal variability of soil $\mathrm{CO}_{2}$ fluxes that is typical for an area of interest and the influence of atmospheric parameters (temperature, pressure, wind, precipitation) on this variability. Automated $\mathrm{CO}_{2}$ flux measurement stations should be deployed where single or multiple chambers measure flux repeatedly over time, in some cases concurrently with meteorological parameters. Correlation analysis can then be used to evaluate the relationship between these parameters.

Numerous environmental parameters influence the biological and physical processes controlling ecological soil $\mathrm{CO}_{2}$ fluxes; however, studies have shown that soil temperature and moisture strongly regulate these fluxes (e.g., Schlesinger, 1977; Edwards and Ross-Todd, 1983; Gordon et al., 1987). Therefore, if the observed relationship between $\mathrm{CO}_{2}$ fluxes and soil temperature and/or moisture can be defined in an ecological model, these environmental parameters can be used to predict $\mathrm{CO}_{2}$ fluxes derived from biological activity in the soil. An important goal here is to establish a baseline of variability of ecological soil $\mathrm{CO}_{2}$ fluxes from a potential $\mathrm{CO}_{2}$ storage site as a function of specific environmental conditions. Variability of soil $\mathrm{CO}_{2}$ fluxes after $\mathrm{CO}_{2}$ 
injection would then be compared to this baseline and, if needed, soil gases could be analyzed for contribution of leaking fossil $\mathrm{CO}_{2}$.

Soil $\mathrm{CO}_{2}$ fluxes, temperature, or moisture content have been observed to be correlated at many sites worldwide. For example, Kicklighter et al. (1994) compiled mean daily soil $\mathrm{CO}_{2}$ flux and soil temperature data from around the world and found that a linear relationship exists between soil temperature and the natural logarithm of $\mathrm{CO}_{2}$ flux. Based on these observations, many ecological models have been developed to describe the relationship between soil $\mathrm{CO}_{2}$ fluxes and temperature or moisture (e.g., Reiners, 1968; Edwards, 1975; Reinke et al., 1981; Rajvashani and Gupta, 1986; Gordon et al., 1987; Norman et al., 1992; Kicklighter et al., 1994; Gouldin et al., 1996) and used to predict soil $\mathrm{CO}_{2}$ fluxes. Application of these models has varied in both the temporal (hourly to annual) and spatial (local to regional) scales considered. It has been shown, however, that the spatial and temporal heterogeneities in $\mathrm{CO}_{2}$ fluxes in the area of interest must be taken into account to minimize error in flux predictions (Kicklighter et al., 1994). At local sites, researchers have found that accumulation chamber $\mathrm{CO}_{2}$ flux measurements and nighttime eddy covariance measurements agree well with soil $\mathrm{CO}_{2}$ fluxes predicted using empirical relationships developed for those sites coupled with environmental parameter measurements (e.g., Norman et al., 1992; Gouldin et al., 1996).

\subsection{Water Chemistry}

Detection of anomalous $\mathrm{CO}_{2}$ related to leakage into ground and surface waters could be accomplished by sampling of these waters and analytical determination of $\mathrm{CO}_{2}$ or of the chemical proxies for $\mathrm{CO}_{2}$. Dissolution of $\mathrm{CO}_{2}$ into ground and surface waters will tend to increase the acidity (decrease the $\mathrm{pH}$ ) of the waters. A relatively large magnitude $\mathrm{CO}_{2}$ leakage flux into ground or surface water could produce $\mathrm{CO}_{2}$ gas bubbles. In this case, gases associated with waters could be sampled and the isotopic compositions $\left(\delta^{13} \mathrm{C}, \Delta{ }^{14} \mathrm{C}\right)$ of $\mathrm{CO}_{2}$ could be determined to constrain the source of $\mathrm{CO}_{2}$ (see description of soil gas carbon isotopic compositions above). However, in the case of small to moderate leakage fluxes, $\mathrm{CO}_{2}$ should be dominantly present in the aqueous phase as dissolved inorganic carbon, DIC (i.e., $\mathrm{CO}_{2}(\mathrm{aq}), \mathrm{H}_{2} \mathrm{CO}_{2}, \mathrm{HCO}_{3}^{-}, \mathrm{CO}_{3}{ }^{2-}$ ). With increasing contribution of leaking $\mathrm{CO}_{2}$ to waters, DIC should similarly increase. Alkalinity is the ability of water to accept protons $\left(\mathrm{H}^{+}\right)$and in most potable natural waters, is predominantly due to the presence of $\mathrm{HCO}_{3}{ }^{-}$and $\mathrm{CO}_{3}{ }^{2-}$. The DIC concentration can be directly determined or can be calculated if both alkalinity and $\mathrm{pH}$ are determined for a given water sample. Recent studies (e.g., Evans et al., 2002) have used plots of DIC concentration versus $\Delta^{14} \mathrm{C}$ of the DIC to trace the addition of deep magmatic carbon to groundwaters containing respirationderived carbon from infiltration. These waters generally fall along mixing trends between waters with relatively low DIC and high $\Delta^{14} \mathrm{C}$ (young biogenic-carbon dominated) and those with relatively high DIC and low $\Delta^{14} \mathrm{C}\left({ }^{14} \mathrm{C}\right.$-free magmatic-carbon dominated $)$. Similar trends would be expected for addition of leaking $\Delta^{14} \mathrm{C}$-free fossil $\mathrm{CO}_{2}$ to groundwaters. If the concentration of DIC derived from a leakage source and water flow rate are known for sample locations, discharge of leakage DIC can be estimated. 
There are numerous factors that may complicate interpretation of ground and surface water geochemistry. Groundwater age should be carefully assessed (e.g., by tritium analyses) in order to determine the influence of residence time on the ${ }^{14} \mathrm{C}$ compositions of DIC. Also, water-rock interactions along flow paths are complex and can influence DIC concentration and isotopic composition, concentrations of major and minor cations in solution, and $\mathrm{pH}$. For example, dissolution of carbonate minerals $\left(\mathrm{CaCO}_{3}\right)$ by the reaction $\mathrm{CO}_{2}+\mathrm{H}_{2} \mathrm{O}+\mathrm{CaCO}_{3}=\mathrm{Ca}^{2+}+$ $2 \mathrm{HCO}_{3}^{-}$results in the doubling of DIC (i.e., one mole of $\mathrm{CO}_{2}$ reacts to produce two moles of $\mathrm{HCO}_{3}^{-}$) and a release of $\mathrm{Ca}^{2+}$ to solution. Also, the ${ }^{13} \mathrm{C}$ and ${ }^{14} \mathrm{C}$ compositions of the DIC produced will reflect contributions from two distinct sources, the $\mathrm{CO}_{2}$ and the carbonate mineral. Therefore, the contribution of DIC derived from dissolution of ${ }^{14} \mathrm{C}$-free carbonate rocks along flow paths would tend to decrease ${ }^{14} \mathrm{C}$ composition similarly to leakage $\mathrm{CO}_{2}$ and could complicate interpretation of DIC concentration- $\Delta^{14} \mathrm{C}$ plots. However, the ${ }^{13} \mathrm{C}$ composition of marine carbonates ( $=0 \pm 4 \%$; Ohmoto and Rye, 1979) is distinct from $\mathrm{CO}_{2}$ from fossil fuels; the $\delta^{13} \mathrm{C}$ values of DIC could therefore be used to distinguish between ${ }^{14} \mathrm{C}$ depletion related to $\mathrm{CO}_{2}$ leakage and carbonate dissolution.

Aqueous geochemical measurements are restricted to point sampling or continuous monitoring at fixed locations. Measurements can be made using portable field equipment (e.g., $\mathrm{pH}$ electrode, field alkalinity titration kit) or by analysis of water samples in a standard geochemical laboratory. Carbon isotopic compositions of water samples are determined as described previously for soilgas samples. The detection range and precision are variable but well established for the various measurements. Measurements are generally inexpensive, ranging from dollars to hundreds of dollars per sample. Aqueous geochemical sampling techniques are long-established, well known, and relatively inexpensive. Yet for groundwater, the spatial distribution of sampling is limited by the presence of wells or springs and interpretation of the chemistry may be complicated by source water chemical composition, rock-water interactions along flow paths, and residence time. For surface waters, complications arise due to source water chemical composition, surface hydrology, and weather.

\subsection{Refinement of Geochemical Sampling Using Statistical Analysis}

Assuming that the sampling method (e.g., IRGA for $\mathrm{CO}_{2}$ concentration, $\mathrm{AC}$ method for soil $\mathrm{CO}_{2}$ flux) has $100 \%$ capability to detect a gas anomaly, the probability $(P)$ of sampling at least once a gas anomaly of area $x$ within an overall sampling area $A$ with $n$ number of randomly distributed point measurements is given by

$$
P=1-\left[1-\frac{x}{A}\right]^{n}
$$

Consequently, to sample a gas anomaly at least once with $95 \%$ confidence where $x / A=0.1, \sim 30$ measurements are required. In the case where $x / A=0.01$ and $0.001, \sim 300$ and 3000 samples are required, respectively. To put these values of $x / A$ in perspective, seepage occurring over 1 
hectare $\left(10^{4} \mathrm{~m}^{2}\right)$ of a $1 \mathrm{~km}^{2}\left(10^{6} \mathrm{~m}^{2}\right)$ sampling area corresponds to $x / A=0.01$. Application of Eq. 6.2 assumes that a gas anomaly exists within area $A$. The case we are particularly interested in here is where near-surface gas monitoring will occur a relatively short time (days to tens of years) after $\mathrm{CO}_{2}$ injection into a deep storage reservoir. This reservoir has presumably been selected due to the very low chances of $\mathrm{CO}_{2}$ leakage from the reservoir within this time period. In this situation, there would likely be a low probability of the existence of a gas anomaly. Bayesian statistics allows us to ask the question: "Given that we have failed to detect $(\sim d)$ a gas anomaly of area $x$ within the sampling area $A$ with one randomly located point measurement, what is the confidence level $(P)$ that it is actually there $(H)$ ?" For this case,

$$
P\langle H \mid \sim d\rangle=\frac{\left(1-\frac{x}{A}\right) P(H)}{P(H)\left[1-\frac{x}{A}\right]+[1-P(H)]}
$$

(Bayes, 1763). This equation is solved by setting $P(H)$ equal to an initial confidence (e.g., 0.1 or 0.9 if realistically pessimistic or optimistic, respectively, that the anomaly is there), given some prior information about the situation of interest. To estimate the number of randomly distributed point measurements $(n)$ necessary for there to be, e.g., only a $5 \%$ chance that an anomaly exists, given that we have not detected it, the calculated $P(H \mid \sim d)$ is substituted for $P(H)$, and the equation is solved iteratively until $P(H \mid \sim d)=0.05$. The number of iterations needed is equal to the number of point measurements $(n)$. If $P(H)=0.1$, likely appropriate for the case where $\mathrm{CO}_{2}$ leakage and seepage from a sequestration reservoir is unlikely a short period of time following injection, $n \approx 7,70,700$, and 7000 for $x / A=0.1,0.01,0.001$, and 0.0001 , respectively. If there is some reason to suspect strongly that an anomaly may exist and $P(H)=0.9, n \approx 50,500,5000$, and 50,000 for $x / A=0.1,0.01,0.001$, and 0.0001 , respectively.

While any number of $x / A$ scenarios may be possible, these examples demonstrate the need to collect prior site-specific geologic information to delineate the most probable gas leakage locations (e.g., near geologic structures or wells) to minimize $A$ and therefore maximize $x / A$. This is particularly important because it is likely that if $\mathrm{CO}_{2}$ leakage and seepage occurs a short period of time after injection, it will be on a small scale (i.e., small $x$ ). The examples presented above also indicate that in the case of preliminary gas sampling and analysis, rapid and economical methods should be used in order to accommodate a potentially large number of measurements.

An additional consideration is that Eq. 6.3 assumes that the sampling methodology is $100 \%$ capable of detecting the gas anomaly. In other words, the detection method does not give false positives (i.e., it detects an anomaly that is not there) or negatives (i.e., it fails to detect an anomaly that is there). In reality, the methods used to detect a $\mathrm{CO}_{2}$ anomaly within background $\mathrm{CO}_{2}$ will likely give both false positives and negatives. In this case, 


$$
P(H \mid \sim d)=\frac{\left[\left(1-\frac{x}{A}\right)(1-\alpha(m))+\frac{x}{A} \beta(m)\right] P(H)}{\left.\left[\left(1-\frac{x}{A}\right)(1-\alpha(m))+\frac{x}{A} \beta(m)\right] P(H)+[1-\alpha(m)] 1-P(H)\right]}
$$

where $\alpha(m)$ and $\beta(m)$ are the false positive and negative rates, respectively, as a function of the magnitude $(m)$ of the anomaly. The confidence that once an anomaly has been detected it is a real anomaly $(P(H \mid \sim d)$, given $\alpha(m)$ and $\beta(m)$ of the detection method, is then given by

$$
P(H \mid d)=\frac{\left[\frac{x}{A}(1-\beta(m))+\left(1-\frac{x}{A}\right) \alpha(m)\right] P(H)}{\left[\frac{x}{A}(1-\beta(m))+\left(1-\frac{x}{A}\right) \alpha(m)\right] P(H)+\alpha(m)[1-P(H)]}
$$

The use of Eqs. 6.4 and 6.5 requires that $\alpha(m)$ and $\beta(m)$ are estimated. For a given measurement method (e.g., $\mathrm{CO}_{2}$ concentration measurement by IRGA), $\alpha(m)$ and $\beta(m)$ are related to the probability distributions of the background and anomalous $\mathrm{CO}_{2}$ concentrations, respectively, and the chosen threshold above which the $\mathrm{CO}_{2}$ concentration is considered anomalous. The probability distributions of the background and anomalous $\mathrm{CO}_{2}$ concentration can be estimated from background field characterization and numerical modeling of $\mathrm{CO}_{2}$ leakage and seepage, respectively, possibly accompanied by small-scale field and laboratory experiments. The threshold value is then found where the influence of $\alpha(m)$ and $\beta(m)$ on $n$ is minimized. Monte Carlo simulation taking $x / A, \alpha(m)$, and $\beta(m)$ into account can be used to estimate the number of measurements that will be required to determine with a desired confidence level that a gas anomaly exists in the sampling area. In the field, the researcher would apply Eqs. 6.4 and 6.5 by beginning with an initial confidence that an anomaly exists within area $A$. Measurements would be made within this area and Eqs. 6.4 or 6.5 would be solved repeatedly, depending on whether an anomaly is not detected or detected, respectively. If the number of measurements that do not detect an anomaly increases, then the confidence that an anomaly exists decreases (Eq. 6.4). Conversely, if the number of measurements that detect an anomaly increases, then so does the confidence that the anomaly exists (Eq. 6.5). Measurements could be made until the desired confidence level is met that an anomaly exists in the sampling area. The use of Eqs. 6.4 and 6.5 therefore has significant potential to guide sampling strategy and reduce the number of high-cost (e.g., isotopic) measurements made. For example, when $\mathrm{CO}_{2}$ concentrations are measured with high confidence of actually being true anomalies related to $\mathrm{CO}_{2}$ leakage and seepage, these sites can then be further sampled for isotopic analyses. Or, if a sufficiently low confidence level that an anomaly exists is reached, then further geochemical analyses can be avoided. Although described in the context of randomly distributed measurements, Eqs. 6.3-6.5 can also be applied 
in the case where measurements are made at evenly spaced intervals along a grid. These equations cannot be applied where spatial clustering of measurements occurs.

\subsection{Integrated Sampling Strategy}

\subsubsection{Introduction}

In this section, we discuss an integrated sampling strategy that appears promising for meeting the fundamental challenge of detecting small $\mathrm{CO}_{2}$ fluxes and concentrations associated with $\mathrm{CO}_{2}$ storage site leakage. We assume that a given land area above the storage structure can be delineated as the area at risk from unintended leakage and seepage. This area, called the study area, will normally include the surface injection facilities and may extend for many kilometers away from surface facilities depending on the depth of the storage reservoir and nature of subsurface structures (e.g., dip of sedimentary beds) and hydrologic systems.

\subsubsection{Baseline Monitoring and Modeling}

Prior to deep $\mathrm{CO}_{2}$ injection, background spatial and temporal variability of subsurface $\mathrm{CO}_{2}$ should be well understood. Figure 6.1 shows the general sampling frequencies and characterization activities. Particular attention should be paid to understanding variability in areas where $\mathrm{CO}_{2}$ leakage and seepage would be most likely (e.g., close to the locations of injection and monitoring wells and geologic features such as faults, lithologic contacts, and springs). Overall, the study area should be characterized with respect to properties that could influence and cause important differences in respiration rates, and thus $\mathrm{CO}_{2}$ concentrations and fluxes. For example, soil type, soil and soil-parent material organic carbon content, vegetation type and density, topography, and surface water hydrology should be mapped and quantified. Remotely sensed and field-mapped data can be organized by using Geographical Information System (GIS) software. If important differences exist across the study area, the area should be divided into sub-regions based on these differences. Ecological modeling (e.g., using the Land Surface Model (LSM) (Bonan, 1996)) should be carried out to develop a consistent conceptual model of the sources and sinks of carbon and moisture within the study area or distinct subregions. Flow and transport modeling (e.g., Oldenburg and Unger, 2003; 2004) should also be performed to understand the flow paths and dispersion processes.

To capture both the overall spatial distribution and the small-scale spatial heterogeneity of soil, $\mathrm{CO}_{2}$ fluxes and concentrations should be measured using the AC method and a portable IRGA, respectively, and soil gases should be collected for chemical and isotopic determinations within the area (or within each sub-region, if appropriate) along a large grid at widely spaced sampling intervals, as well as along a smaller grid at closely spaced sampling intervals. These measurements should also be made repeatedly over time at several fixed "representative" sites to capture diurnal to seasonal variations. The carbon isotopic compositions of soil and sub-soil organic matter should be determined within the study area and measured repeatedly over time at several representative sites. In addition, pre-existing wells within the study area should be sampled to characterize background sub-soil gas chemistry and isotopic compositions (e.g., $\mathrm{CO}_{2}$ and $\mathrm{O}_{2}$ concentrations, $\delta^{13} \mathrm{C}$, and $\Delta^{14} \mathrm{C}$-depth profiles). 
Soil temperature and moisture (at $>10 \mathrm{~cm}$ depth to avoid the effects of rapid soil drying) should be monitored contemporaneously with fluxes. Atmospheric temperature, pressure, and wind speed and direction should also be measured at a weather station concurrently with soil $\mathrm{CO}_{2}$ fluxes by the $\mathrm{AC}$ method. Correlation analysis of $\mathrm{CO}_{2}$ flux and environmental parameters should be performed. Using regression analysis, empirical relationships between correlated parameters could be established for the overall area, or each sub-region, if appropriate, and used to predict the background $\mathrm{CO}_{2}$ fluxes expected under a given set of environmental conditions.

If the study area meets the terrain conditions required by the EC method, such as relatively low slopes $(<8-15 \%)$ and horizontally homogeneous vegetation type and density, then an EC station should be deployed during times of meteorologically stable conditions to characterize spatially averaged background $\mathrm{CO}_{2}$ fluxes. The background temporal variability of these fluxes should be established by making measurements over diurnal to seasonal cycles. Alternatively, if the study area overall has no horizontally homogeneous terrain, but can be divided into sub-regions within which homogeneous terrain is found, then EC instrumentation could be deployed to characterize the background $\mathrm{CO}_{2}$ fluxes within each sub-region. In practical applications under conditions typically encountered in the field, EC measurements are somewhat uncertain and the method cannot be counted on to detect unequivocally small $\mathrm{CO}_{2}$ flux variations due to leakage and seepage. Eddy covariance $\mathrm{CO}_{2}$ fluxes should be compared to average $\mathrm{CO}_{2}$ fluxes measured by the $\mathrm{AC}$ method within the same footprint area to quantify the component of the background EC flux derived from soil and subsoil respiration.

\subsubsection{Longterm Monitoring}

As shown in Figure 6.1, a range of measurements should be made during and after $\mathrm{CO}_{2}$ injection into the storage reservoir at frequencies that will likely change with time following injection. The time over which such monitoring activities will need to be carried out is highly uncertain, and we have indicated this in Figure 6.1 by the lightening of the symbols after 100 years. During and after $\mathrm{CO}_{2}$ injection, monitoring for $\mathrm{CO}_{2}$ leakage and seepage should focus on rapid, economical, low-error measurements of soil $\mathrm{CO}_{2}$ concentration and surface $\mathrm{CO}_{2}$ fluxes along grids at evenly spaced intervals. The objective is to minimize the number of these measurements $(n)$ and then further focus more costly deep sampling and isotopic measurements on "high-probability" anomalies (Eqs. 6.4 and 6.5). To accomplish this, $x / A$ (Eqs. 6.4 and 6.5, in the case where measurement methods are not $100 \%$ capable of detecting anomalous $\mathrm{CO}_{2}$ ) should be maximized by focusing soil $\mathrm{CO}_{2}$ concentration and $\mathrm{AC} \mathrm{CO}_{2}$ flux sampling on the most high-risk areas for $\mathrm{CO}_{2}$ leakage and seepage (e.g., near injection and other wells, geologic structures, and suspected seepage areas). Secondly, the probability distributions of the background and anomalous soil $\mathrm{CO}_{2}$ concentration (or flux) should be estimated from background field characterization and numerical modeling of $\mathrm{CO}_{2}$ leakage and seepage, respectively, and threshold values should be defined above which these parameters are considered anomalous. These $\mathrm{CO}_{2}$ concentration and flux threshold values are chosen based on minimization of $\alpha(m)$ and $\beta(m)$ and therefore $n$ (Eqs. 6.4 and 6.5). Equations 6.4 and 6.5 should then be used to determine the presence (or absence) of $\mathrm{CO}_{2}$ anomalies with high confidence. 
While installation of wells or trenches for sub-soil gas chemical analysis and carbon isotopic analyses of soil and sub-soil $\mathrm{CO}_{2}$ may have relatively high potential to detect leaking fossil $\mathrm{CO}_{2}$, these are relatively time and cost-intensive methods. Integrated data analysis of the more efficient soil- $\mathrm{CO}_{2}$ concentration and flux measurements should therefore be used to determine where soil gases should be collected for carbon isotopic analyses and wells should be installed for sub-soil gas sampling. Anomalous $\mathrm{CO}_{2}$ concentrations and fluxes should be detected with high probability (Eq. 6.5). In addition, maps of sampling areas should be contoured for soil $\mathrm{CO}_{2}$ concentration and flux magnitude and autocorrelation and cross-correlation coefficients of these parameters. Furthermore, measured $\mathrm{CO}_{2}$ fluxes should be compared to the behavior of background $\mathrm{CO}_{2}$ fluxes predicted by ecological models such as LSM (Bonan, 1996) under a given set of atmospheric parameters and assessed for deviations from this behavior. Based on these combined analyses, the locations of more costly and time-intensive sampling can be determined.

Where anomalously high soil $\mathrm{CO}_{2}$ concentration and flux are located, gases should be sampled at regular intervals from the surface to the water table for chemical and carbon isotopic compositions. An increase in $\mathrm{CO}_{2}$ concentration with depth would indicate $\mathrm{CO}_{2}$ production at depth. Measured $\mathrm{CO}_{2}$ and $\mathrm{O}_{2}$ concentration-depth profiles should be compared to profiles generated by diffusion models of background $\mathrm{CO}_{2}$ respiration and $\mathrm{O}_{2}$ consumption to evaluate a biological respiration source of $\mathrm{CO}_{2}$ at (sub-soil) depth. Profiles of $\delta^{13} \mathrm{C}$ and $\Delta^{14} \mathrm{C}$ should be measured. Carbon-13 values at sub-soil depths should be compared to values for soil $\mathrm{CO}_{2}$ and organic matter to look for differences that may indicate a distinct source. Very low $\Delta^{14} \mathrm{C}$ values would be expected at depth with a leaking fossil $\mathrm{CO}_{2}$ source and the fraction contribution of this component to sampled $\mathrm{CO}_{2}$ could be estimated by mass balance calculations. Importantly, the potential contribution of $\mathrm{CO}_{2}$ derived from oxidation of ancient sedimentary organic matter should also be evaluated. Overall, the observations of $\mathrm{CO}_{2}$ and $\mathrm{O}_{2}$ concentration gradients, $\mathrm{CO}_{2}$ production distribution, surface $\mathrm{CO}_{2}$ fluxes, and carbon isotopic compositions must be consistent with the $\mathrm{CO}_{2}$ source.

Providing that the terrain conditions in the study area are such that the errors of EC measurements are sufficiently low to detect potentially small seepage fluxes, EC should be used in conjunction with $\mathrm{AC}$ and soil $\mathrm{CO}_{2}$ concentration measurements to search for $\mathrm{CO}_{2}$ seepage. In the case where the spatially averaged $\mathrm{EC}$ flux is sufficiently higher than background variability to be considered anomalous, $\mathrm{AC}$ and soil $\mathrm{CO}_{2}$ concentration measurements should be used detect the location and extent of the anomaly within the EC footprint. So that $x / A$ and therefore the number of $\mathrm{AC}$ and $\mathrm{CO}_{2}$ concentration measurements are minimized, the $\mathrm{EC}$ instrumentation (e.g., tower height) should be configured such that footprint areas are relatively small.

\section{CONCLUSIONS}

A great deal of general knowledge exists about the properties, detection, and monitoring of $\mathrm{CO}_{2}$ and other common gases. Furthermore, through numerical simulation of $\mathrm{CO}_{2}$ flow and transport, we have plausible expectations about how $\mathrm{CO}_{2}$ leakage and seepage from geologic storage sites will manifest itself in the near-surface in terms of fluxes and concentrations. Despite this 
knowledge and understanding, the fact of the matter is that discerning small anomalous $\mathrm{CO}_{2}$ fluxes and concentrations $\left(\mathrm{CO}_{2}\right.$ LOSS $)$ from natural background variations will be challenging. The strategy that we propose involves comprehensive baseline monitoring and modeling to develop a sound understanding and predictive capability for the natural system in the absence of any $\mathrm{CO}_{2}$ leakage and seepage. Because (1) large-scale $\mathrm{CO}_{2}$ leakage and seepage from geologic $\mathrm{CO}_{2}$ storage sites is unlikely, (2) travel times to the surface in the scenarios involving flow through the stratigraphic section will be long, and (3) large-scale geologic $\mathrm{CO}_{2}$ storage is still many years away, there is ample time to develop the knowledge and understanding of natural systems at potential $\mathrm{CO}_{2}$ storage sites that could be impacted by $\mathrm{CO}_{2}$ leakage and seepage. Once this understanding is achieved and geologic $\mathrm{CO}_{2}$ storage begins, a program of multiple and integrated measurement, monitoring, and sampling technologies can be applied during the injection period and after for some time yet to be determined. Measurements in conflict with expectations of the natural system should be investigated thoroughly by detailed vertical profile sampling and isotopic analyses, the results of which can definitively determine if the source is a deep fossilfuel- $\mathrm{CO}_{2}$ source consistent with a geologic $\mathrm{CO}_{2}$ storage site.

\section{ACKNOWLEDGMENTS}

We thank Pat Dobson, Larry Myer, Margaret Torn, and Sally Benson (LBNL) for constructive comments and reviews of this report. This work was supported by the Office of Science, U.S. Department of Energy under Contract No. DE-AC03-76SF00098.

\section{REFERENCES}

Alexander, M., Introduction to Soil Microbiology, $2^{\text {nd }}$ ed., John Wiley and Sons, New York, 467 pp., 1977.

Amundson, R.G. and V.S. Smith, Annual cycles of physical and biological properties in an uncultivated and irrigated soil in the San Joaquin Valley of California, Agriculture, Ecosystems, Env., 20, 195-208, 1988.

Amundson, R.G., O.A. Chadwick, and J.M. Sowers, A comparison of soil climate and biological activity along an elevation gradient in the eastern Mojave Desert, Oecologia, 80, 395-400, 1989.

Amundson, R.G. and E.A. Davidson, Carbon and nitrogeneous gases in the soil atmosphere, $J$. Geochem. Explor., 38, 13-41, 1990.

Anderson, D.E. and and C.D. Farrar, Eddy covariance measurement of $\mathrm{CO}_{2}$ flux to the atmosphere from an area of high volcanogenic emissions, Mammoth Mountain, California, Chem. Geology, $177,31-42,2001$.

Baldocchi, D., Assessing the eddy covariance technique for evaluating carbon dioxide exchange rates of ecosystems: past, present, and future, Global Change Biology, 9, 479-492, 2003. 
Baldocchi, D.D., and T.P. Myers, On using eco-physiological, micrometerological and biogeochemical theory to evaluate carbon dioxide, water vapor and trace gas fluxes over vegetation: a perspective, Agricultural and Forest Meteorology, 90, 1-25, 1998.

Baldocchi, D.D., Hicks, B.B. and Meyers, T.P., Measuring biosphere-atmosphere exchanges of biologically related gases with micrometeorological methods, Ecology, 69, 1331-1340, 1988.

Baldocchi, D.D., R. Valentini, S. Running, W. Oechel, and R. Dahlman, Strategies for measuring and modeling carbon dioxide and water vapor fluxes over terrestrial ecosystems, Global Change Biology, 2, 159-168, 1996.

Baldocchi, D.D. and K.B. Wilson, Modeling $\mathrm{CO}_{2}$ and water vapor exchange of a temperate broadleaved forest across hourly to decadal time scales, Ecological Modelling, 142, 155-184, 2001 .

Baldocchi, D.D, E. Falge, L., Gu, , R. Olson, D. Hollinger, S. Running, P. Anthoni, Ch. Bernhofer, K. Davis, J. Fuentes, A. Goldstein, G. Katul, B. Law, X. Lee, Y. Malhi, T. Meyers, J.W. Munger, W. Oechel, K. Pilegaard, H.P. Schmid, R. Valentini, S. Verma, T. Vesala, K. Wilson and S. Wofsy, 2001, FLUXNET: A New Tool to Study the Temporal and Spatial Variability of Ecosystem-Scale Carbon Dioxide, Water Vapor and Energy Flux Densities, Bull. Am. Meteorol. Soc., 82, 2415-2435, 2001.

Bayes, T., An essay towards solving a problem in the doctrine of Chances, Phil. Trans. of the Royal Society of London, 53, 370-418, 1763.

Bonan, G.B., A land surface model (LSM version 1.0) for ecological, hydrological, and atmospheric studies: Technical description and user's guide, TN-417+STR, NCAR, Boulder, CO, 1996.

Britter, R.E., Atmospheric dispersion of dense gases, Ann. Rev. Fluid Mech., 21, 317-344, 1989.

Chiodini, G., G. R. Cioni, M. Guidi, B. Raco, and L. Marini, Soil $\mathrm{CO}_{2}$ flux measurements in volcanic and geothermal areas, Appl. Geochem., 13, 543-552, 1998.

Chiodini, G., C. Cardellini, F. Frondini, D. Granieri, L. Marini, and G. Ventura, $\mathrm{CO}_{2}$ degassing and energy release at Solfatara Volcano, Campi Flegrei, Italy, J. Geophys. Res., 106, 16,213-16,221, 2001 .

Duarte, F.J., Tunable Laser Applications, Optical Engineering Series No.50, Marcel Dekker, Inc., New York, NY, 1995.

Edwards, N.T., Effects of temperature and moisture on carbon dioxide evolution in a mixed deciduous forest floor, Soil Sci. Soc. Am. Proc., 39, 361-365, 1975.

Edwards, N.T. and B.M. Ross-Todd, Soil carbon dynamics in a mixed deciduous forest following clear-cutting with and without residual removal, Soil Sci. Soc. Am. J., 47, 1014-1021, 1983.

Edwards, N.T. and J.S. Riggs, Automated monitoring of soil respiration: a moving chamber design, Soil Sci. Soc. Am. J., 67, 1266-1271, 2003.

Evans, W. C., M. L. Sorey, A. C. Cook, B. M. Kennedy, D. L. Shuster, E. M. Colvard, L. D. Wjite, and M. L. Huebner, Tracing and quantifying magmatic carbon discharge in cold groundwaters: lessons learned from Mammoth Mountain, USA, J. Volcanol. Geother, Res., 114, 291-312, 2002. 
Farrar, C. D., M. L. Sorey, W. C. Evans, J. F. Howle, B. D. Kerr, B. M. Kennedy, Y. King, and J. R. Southon, Forest-killing diffuse $\mathrm{CO}_{2}$ emission at Mammoth Mountain as a sign of magmatic unrest, Nature, 376, 675-678, 1995.

Faure, G., Principles of Isotope Geochemistry, John Wiley and Sons, New York, NY, 1986.

Foken, Th. and B. Wichura, Tools for quality assessment of surface-based flux measurements, Agric. For. Meteorol., 78, 83-105, 1996.

Gordon, A.M., R.E. Schlentner, and K. Van Cleve, Seasonal patterns of soil respiration and $\mathrm{CO}_{2}$ evolution following harvesting in the white spruce forests of interior Alaska, Can. J. For. Res., 17, 304-310, 1987.

Gouldin, M.L., J.W. Munger, S.-M. Fan, B.C. Daube, and S.C. Wofsy, Measurements of carbon sequestration by long-term eddy covariance: methods and a critical evaluation of accuracy, Global Change Biology, 2, 169-182, 1996.

Gouldin, M.L. and P.M. Crill, Automated measurements of $\mathrm{CO}_{2}$ exchange at the moss surface of a black spruce forest, Tree Physiology, 17, 537-542, 1997.

Hepple, R. and S.M. Benson, Implications of surface seepage on the effectiveness of geologic storage of carbon dioxide as a climate change mitigation strategy, in Greenhouse Gas Control Technologies, edited by J. Gale and Y. Kaya, pp. 261-266, Elsevier Science, New York, 2002.

Hinkle, M.E., Environmental conditions affecting concentrations of $\mathrm{He}, \mathrm{CO}_{2}, \mathrm{O}_{2}$, and $\mathrm{N}_{2}$ in soil gases, Appl. Geochem., 9, 53-63, 1994.

Hoefs, J., Stable Isotope Geochemistry, Springer-Verlag, New York, NY, 1987.

Keller, C.K., Hydrogeochemistry of a clayey till, 2, Sources of $\mathrm{CO}_{2}$, Water Resour. Res., 27, 2555-2564, 1991.

Keller, C.K. and D.H. Bacon, Soil respiration and georespiration distinguished by transport analyses of vadose $\mathrm{CO}_{2},{ }^{13} \mathrm{CO}_{2}$, and ${ }^{14} \mathrm{CO}_{2}$, Global Biogeochem. Cycles, 12, 361-372, 1998.

Kicklighter, D.W., J.M. Melillo, W.T. Peterjohn, E.B. Rastetter, A.D McGuire, and P.A. Steudler, Aspects of spatial and temporal aggregation in estimating regional carbon dioxide fluxes from temperate forest soils, J. Geophys. Res., 99, 1303-1315, 1994.

Kucera, C.L. and D.L. Kirkham, Soil respiration studies in tallgrass prairie in Missouri, Ecology, 52, 912-915, 1971.

Lenschow, D.L., Micrometeorological techniques for measuring biosphere-atmosphere trace gas exchange. In Biogenic Trace Gases: Measuring Emissions from Soil and Water edited by P.A. Matson and R.C. Harriss, Blackwell Science, Cambridge, 126-163, 1995.

Lewicki, J.L., W.C. Evans, G.E. Hilley, M.L. Sorey, J.D. Rogie, and S.L. Brantley, Shallow soil $\mathrm{CO}_{2}$ flow along the San Andreas and Calaveras faults, California, J. Geophys. Res., 108, ECV 3-1 - ECV 3-14, 2003a.

Lewicki, J.L., C. Connor, K. St-Amand, J. Stix, and W. Spinner, Self-potential, soil $\mathrm{CO}_{2}$ flux, and temperature on Masaya volcano, Nicaragua, Geophys. Res. Lett., 30, 1817, 2003 b. 
LI-COR Product Information Brochure, 2003. http://env.licor.com.

Magee, J.W., J.A. Howley, and J.F. Ely, A predictive model for the thermophysical properties of carbon dioxide rich mixtures, Research Report RR-136, Gas Processors Assoc., Tulsa OK, 35 pp., 1994.

Martini, B.A., D.C. Potts, E.A. Silver, and W.L. Pickles, Hyperspectral Remote Sensing for Research and Monitoring in Active Volcanic Regions: Long Valley Caldera, CA. EOS Trans. Am. Geophys. Union, Fall Meeting p. F1385, 2000.

Massmann, J., and D. Farrier, Effects of atmospheric pressures on gas transport in the vadose zone, Water Resour. Res., 28, 777-791, 1992.

Massmann, W.J., and X. Lee, Eddy covariance flux corrections and uncertainties in long term studies of carbon and energy exchanges, Agric-For-Meteorol., 113, 121-144, 2002.

Mogensen, V.O., Field measurements of dark respiration rates of roots and aerial parts in Italian ryegrass and barley, J. Appl. Ecol., 14, 243-252, 1977.

Mosier, A.R., Chamber and isotope techniques, in Exchange of trace gases between ecosystems and the atmosphere, edited by M.O. Andreae, and D.S. Schimel, J. Wiley and Sons, 1989.

Norman, J.M., R. Garcia, and S.B. Verma, Soil surface $\mathrm{CO}_{2}$ fluxes and the carbon budget of a grassland, J. Geophys. Res., 97, 18,845-18,853, 1992.

NIST (National Institute of Science and Technology), NIST Database 14 Mixture Property Database, version 9.08, U.S. Department of Commerce, Oct. 1992.

Ohmoto, H. and R.O. Rye, Isotopes of sulfur and carbon, in Geochemistry of hydrothermal ore deposits, edited by H.L. Barnes, pp. 509-567, John Wiley and Sons, New York, 1979.

Oldenburg, C.M., and A.J.A. Unger, On leakage and seepage from geologic carbon sequestration sites: unsaturated zone attenuation, Vadose Zone Journal, 2, 287-296, 2003.

Oldenburg, C.M., and A.J.A. Unger, Coupled Vadose Zone and Atmospheric Surface-Layer Transport of $\mathrm{CO}_{2}$ from Geologic Carbon Sequestration Sites, Vadose Zone Journal, 3, 848-857, 2004.

O’Leary, M.H., Carbon isotopes in photosynthesis, Bioscience, 38, 328-336, 1988.

Oskarsson, N., K. Palsson, H. Olafsson, and T. Ferreira, Experimental monitoring of carbon dioxide by low power IR-sensors: Soil degassing in the Funas Volcanic Centre, Azores, $J$. Volcanol. Geotherm. Res., 92, 195-207, 1999.

Osozawa, S. and S. Hasegawa, Diel and seasonal changes in carbon dioxide concentration and flux in an andisol, Soil Science, 160, 117-124, 1995.

Parada, C.B., A. Long, and S.N. Davis, Stable-isotopic compositions of soil carbon dioxide in the Tucson Basin, Arizona, U.S.A., Isot. Geosci., 1, 219-236, 1983.

Pruess, K., C. Oldenburg, and G. Moridis, TOUGH2 User's Guide Version 2.0, Lawrence Berkeley National Laboratory Report LBNL-43134, 197 pp., November 1999. 
Radziemski, L. J., Richard W. Solarz, and Jeffrey A. Paisner, Laser Spectroscopy and Its Applications, Optical Engineering Series No. 11, Marcel Dekker, NY, 1987.

Rajvashani, R. and S.R. Gupta, Soil respiration and carbon balance in a tropical Dalbergia sisso forest ecosystem, Flora, 178, 251-260, 1986.

Reimer, G.M. Use of soil-gas helium concentrations for earthquake prediction: Limitations imposed by diurnal variation, J. Geophys. Res., 85, 3107-3114, 1980.

Reiners, W.A., Carbon dioxide evolution from the floor of three Minnesota forests, Ecology, 49, 471-483, 1968.

Reinke, J.J., D.C. Adiano, and K.W. McLeod, Effects of litter alteration on carbon dioxide evolution from a South Carolina pine forest floor, Soil Sci. Soc. Am. J., 45, 620-623, 1981.

Rogie, J.D., D.M. Kerrick, M.L. Sorey, G. Chiodini, and D.L. Galloway, Dynamics of carbon dioxide emission at Mammoth Mountain, California, Earth Planet. Sci. Lett., 188, 535-541, 2001.

Rolston, D.E., Gas flux, in "Methods of Soil Analysis, 1, Physical and Mineralogical Methods," edited by A. Klute, Am. Soc. Agron. Monogr., 9, 1103-1119, 1986.

Salazar, J. M., P. A. Hernandez, N. M. Perez, G. Melian, J. Alvarez, F. Segura, and K. Notsu, Diffuse emission of carbon dioxide from Cerro Negro volcano, Nicaragua, Central America, Geophys. Res. Lett., 22, 4275-4278, 2001.

Schery, S. D., D. H. Gaeddert, and M. H. Wilkening, Factors affecting exhalation of radon from a gravelly sandy loam, J. Geophys. Res., 89, 7299-7309, 1984.

Schlesinger, W.H., Carbon balance in terrestrial detritus, Annu. Rev. Ecol. Syst., 8, 51-81, 1977.

Schlessinger, M., Infrared Technology Fundamentals, $2^{\text {nd }} E d$., Revised and Expanded, Optical Engineering Series No.46, Marcel Dekker, Inc., New York, NY, 1995.

Shuler, P.J. and Y. Tang, Atmospheric CO2 Monitoring Systems - A Critical Review of Available Techniques and Technology Gaps: Report for SMV Group, The CO2 Capture Project (CCP), 2002.

Singh, J.S. and S.R. Gupta, Plant decomposition and soil respiration in terrestrial ecosystems, Bot. Rev., 43, 449-528, 1977.

Slade, D.H., (editor), Meteorology and Atomic Energy 1968, Chapter 2, U.S. Atomic Energy Commission, 1968.

Sorey, M.L., C.D. Farrar, W.C. Evans, D.P. Hill, R.A. Bailey, J.W. Hendley II, and P.H. Stauffer, Invisible $\mathrm{CO}_{2}$ gas killing trees at Mammoth Mountain, California, U.S. Geological Survey Fact Sheet 172-96, 4pp., 1996. http://wrgis.wr.usgs.gov/fact-sheet/fs172-96/.

Southon, J.R., J.S. Vogel, S.E. Trumbore, J.C. Davis, M.L. Roberts, M.W. Caffee, R.C. Finkel, I.D. Proctor, D.W. Heikkinen, A.J. Berno, and R.S. Hornady, Progress in AMS measurements at the LLNL spectrometer, Radiocarbon, 34, 473-477, 1993.

Spycher, N., K. Pruess, and J. Ennis-King, $\mathrm{CO}_{2}-\mathrm{H}_{2} \mathrm{O}$ mixtures in geological sequestration of $\mathrm{CO}_{2}$. 
Assesment and calculation of mutual solubilities from 12 to $100{ }^{\circ} \mathrm{C}$ and up to 600 bar, Geochimica et Cosmochimica Acta, 67(16), 3015-3031, 2003.

Trumbore, S., Age of soil organic matter and soil respiration: radiocarbon constraints on belowground dynamics, Ecological Applications, 10, 399-411, 2000.

USGS, Measuring volcanic gases: emission rates of sulfur dioxide and carbon dioxide in volcanic plumes, 2000a. http://volcanoes.usgs.gov/About/What/Monitor/Gas/plumes.html.

USGS, Measuring volcanic gases: $\quad$ soil efflux, $2000 \mathrm{~b}$. http://volcanoes.usgs.gov/About/What/Monitor/Gas/soil.html.

Van Genuchten, M.T., A closed-form equation for predicting the hydraulic conductivity of unsaturated soils, Soil Sci. Soc. Am. J., 44, 892-898, 1980.

Vargaftik, N.B., Y.K. Vinogradov, and V.S. Yargin, Handbook of Physical Properties of Liquids and Gases, Third Edition, Begell House, New York, 1359 pp., 1006, 1996.

Webb, S.W., and J.M. Phelan, Effect of weather on the predicted landmine chemical signature for Kabul, Afghanistan, Sandia National Laboratories Report SAND2002-3779, 2002.

Wiant, H.V., Influence of temperature on the rate of soil respiration, J. For., 65, 489-490, 1967a.

Wiant, H.V., Influence of moisture content on the "soil respiration", J. For., 65, 902-903, 1967 b.

Wood, W.W. and M.J. Petraitis, Origin and distribution of carbon dioxide in the unsaturated zone of the southern high plains of Texas, Water Resour. Res., 20, 1193-1208, 1984.

Wood, B.D., C.K. Keller, and D.L. Johnstone, In situ measurement of microbial activity and contrals on microbial $\mathrm{CO}_{2}$ production in the unsaturated zone, Water Resour. Res., 29, 647-659, 1993. 


\section{TABLES}

Table 3.1. Hydrogeological properties of the unsaturated zone for the base case.

\begin{tabular}{ll}
\hline \multicolumn{1}{c}{ Property } & \multicolumn{1}{c}{ Value } \\
\hline Permeability $\left(k_{r}=k_{Z}\right)$ & $1 \times 10^{-12} \mathrm{~m}^{2}$ (1 Darcy) \\
Porosity $(\phi)$ & 0.2 \\
Infiltration rate $(i)$ & $10.0 \mathrm{~cm} \mathrm{yr}^{-1}$ \\
Residual water saturation $\left(S_{l r}\right)$ & 0.1 \\
Residual gas saturation $\left(S_{\mathrm{gr}}\right)$ & 0.01 \\
van Genuchten $(1980) \alpha$ & $1 \times 10^{-4} \mathrm{~Pa}^{-1}$ \\
van Genuchten $(1980) m$ & 0.2 \\
\hline
\end{tabular}

Table 3.2. Properties of the coupled subsurface-surface-layer model system.

\begin{tabular}{|c|c|}
\hline Property & Value \\
\hline \multicolumn{2}{|l|}{ Subsurface } \\
\hline Subsurface region extent $(x \times y \times z)$ & $1 \mathrm{~km} \times 1 \mathrm{~m}, 0 \mathrm{~m}<z<35 \mathrm{~m}$ \\
\hline Discretization $(N x \mathrm{x} N y \mathrm{x} N z)$ & $100 \times 1 \times 35$ \\
\hline Permeability $\left(k_{X}=k_{Z}\right)$ & $1 \times 10^{-12} \mathrm{~m}^{2}$ \\
\hline Porosity $(\phi)$ & 0.2 \\
\hline Infiltration rate $(i)$ & $10 \mathrm{~cm} \mathrm{yr}^{-1}$ \\
\hline $\mathrm{CO}_{2}$ flux region & $450 \mathrm{~m}<x<550 \mathrm{~m}$ \\
\hline $\mathrm{CO}_{2}$ mass flux & $4.04 \times 10^{-6} \mathrm{~kg} \mathrm{~m}^{-2} \mathrm{~s}^{-1}$ \\
\hline Residual water sat. $\left(S_{l r}\right)$ & 0.1 \\
\hline Residual gas sat. $\left(S_{\text {gr }}\right)$ & 0.01 \\
\hline van Genuchten (1980) $\alpha$ & $1 \times 10^{-4} \mathrm{~Pa}^{-1}$ \\
\hline van Genuchten (1980) $m$ & 0.2 \\
\hline \multicolumn{2}{|l|}{ Surface Layer } \\
\hline Surface-layer region extent $(x \times y \times z)$ & $1 \mathrm{~km} \times 1 \mathrm{~m}, 35 \mathrm{~m}<z<45 \mathrm{~m}$ \\
\hline Discretization $(N x \times N y \times N z)$ & $100 \times 1 \times 20$ \\
\hline Pressure in surface layer & 1 bar \\
\hline Temperature (isothermal) & $15^{\circ} \mathrm{C}$ \\
\hline Velocity profile & logarithmic \\
\hline Reference velocity at $z=10 \mathrm{~m}$ & 1,3, or $5 \mathrm{~m} \mathrm{~s}^{-1}$ \\
\hline Friction velocity for $u_{x}=1 \mathrm{~m} \mathrm{~s}^{-1}$ & $0.0868 \mathrm{~m} \mathrm{~s}^{-1}$ \\
\hline Friction velocity for $u_{x}=5 \mathrm{~m} \mathrm{~s}^{-1}$ & $0.434 \mathrm{~m} \mathrm{~s}^{-1}$ \\
\hline Reference height $\left(z_{0}\right)$ & $0.10 \mathrm{~m}$ \\
\hline
\end{tabular}


Table 6.1. Chemical and isotopic signatures related to $\mathrm{CO}_{2}$ derived from different sources.

\begin{tabular}{|c|c|c|c|c|c|}
\hline $\mathrm{CO}_{2}$ source & $\begin{array}{c}\delta^{13} \mathrm{C}_{\mathrm{CO} 2} \\
\% 0\end{array}$ & $\begin{array}{c}\Delta{ }^{14} \mathrm{C}_{\mathrm{CO} 2} \\
\% \text { oo }\end{array}$ & $\begin{array}{l}\text { Near- } \\
\text { surface } \\
\mathrm{CO}_{2} \text { conc. }\end{array}$ & $\begin{array}{l}\mathrm{CO}_{2} \text { conc. } \\
\text { profile with } \\
\text { depth }\end{array}$ & $\begin{array}{l}\mathrm{O}_{2} \text { conc. } \\
\text { profile with } \\
\text { depth }\end{array}$ \\
\hline Atmosphere & -7 & 70 & Low & - & - \\
\hline $\begin{array}{l}\text { Plant root } \\
\text { respiration and } \\
\text { oxidative decay } \\
\text { of young soil } \\
\text { organic matter }\end{array}$ & $\begin{array}{l}C_{3}:-24 \text { to }-38 \\
C_{4}:-6 \text { to }-19\end{array}$ & $\geq 70$ & $\begin{array}{l}\text { Low to } \\
\text { moderate }\end{array}$ & $\begin{array}{l}\text { Increasing } \\
\text { through soil } \\
\text { zone }\end{array}$ & $\begin{array}{l}\text { Decreasing } \\
\text { through soil } \\
\text { zone }\end{array}$ \\
\hline $\begin{array}{l}\text { Oxidative decay } \\
\text { of ancient } \\
\text { organic matter }\end{array}$ & $\begin{array}{l}\mathrm{C}_{3}:-24 \text { to }-38 \\
\text { Aquatic/ } \mathrm{C}_{4}:-6 \\
\text { to }-19 \\
\text { Also age } \\
\text { dependent }\end{array}$ & $\begin{array}{l}\text { Highly } \\
\text { depleted to } \\
\text { absent, } \\
\text { depending } \\
\text { on age }\end{array}$ & Low & $\begin{array}{l}\text { Increasing } \\
\text { potentially } \\
\text { through } \\
\text { vadose zone }\end{array}$ & $\begin{array}{l}\text { Decreasing } \\
\text { potentially } \\
\text { through } \\
\text { vadose zone }\end{array}$ \\
\hline $\begin{array}{l}\text { Marine } \\
\text { carbonate rocks }\end{array}$ & $0 \pm 4$ & absent & Low & $\begin{array}{l}\text { Increasing } \\
\text { through } \\
\text { vadose zone }\end{array}$ & No effect \\
\hline Fossil fuel & Average: -27 & absent & $\begin{array}{l}\text { Moderate } \\
\text { to high }\end{array}$ & $\begin{array}{l}\text { Increasing } \\
\text { through } \\
\text { vadose zone }\end{array}$ & No effect \\
\hline
\end{tabular}

Conc., $\mathrm{C}_{3}$, and $\mathrm{C}_{4}$, refer to concentration, $\mathrm{C}_{3}$ plants, and $\mathrm{C}_{4}$ plants. All near-surface concentrations given are general estimates; these concentrations will be strongly dependent on the magnitude of the $\mathrm{CO}_{2}$ flux. 


\section{FIGURES}

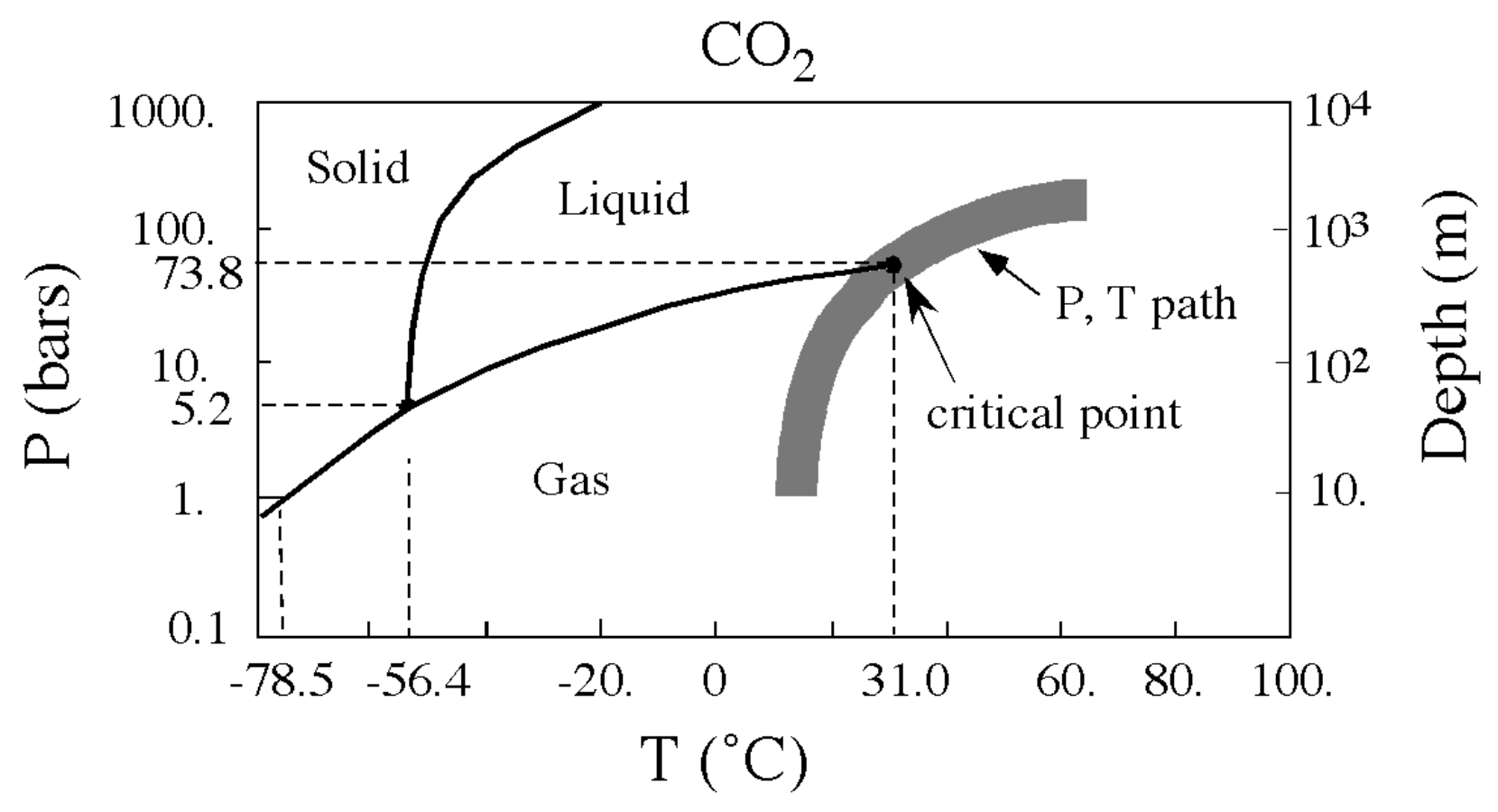

Figure 2.1. Phase diagram for $\mathrm{CO}_{2}$ showing typical $\mathrm{P}-\mathrm{T}$ path with depth in the earth. 


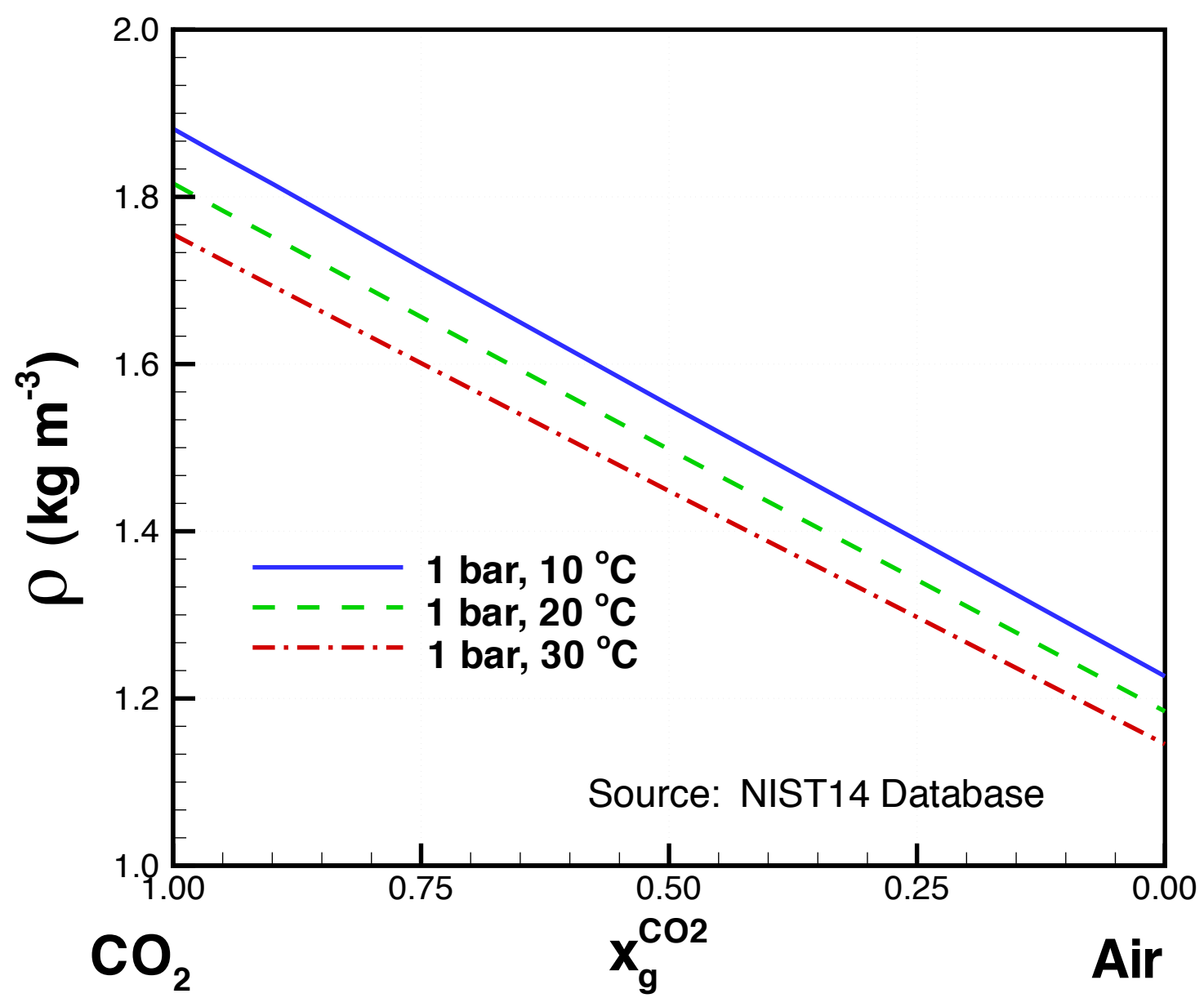

Figure 2.2. Density as a function of concentration (mole fraction) in the system $\mathrm{CO}_{2}$-air. 


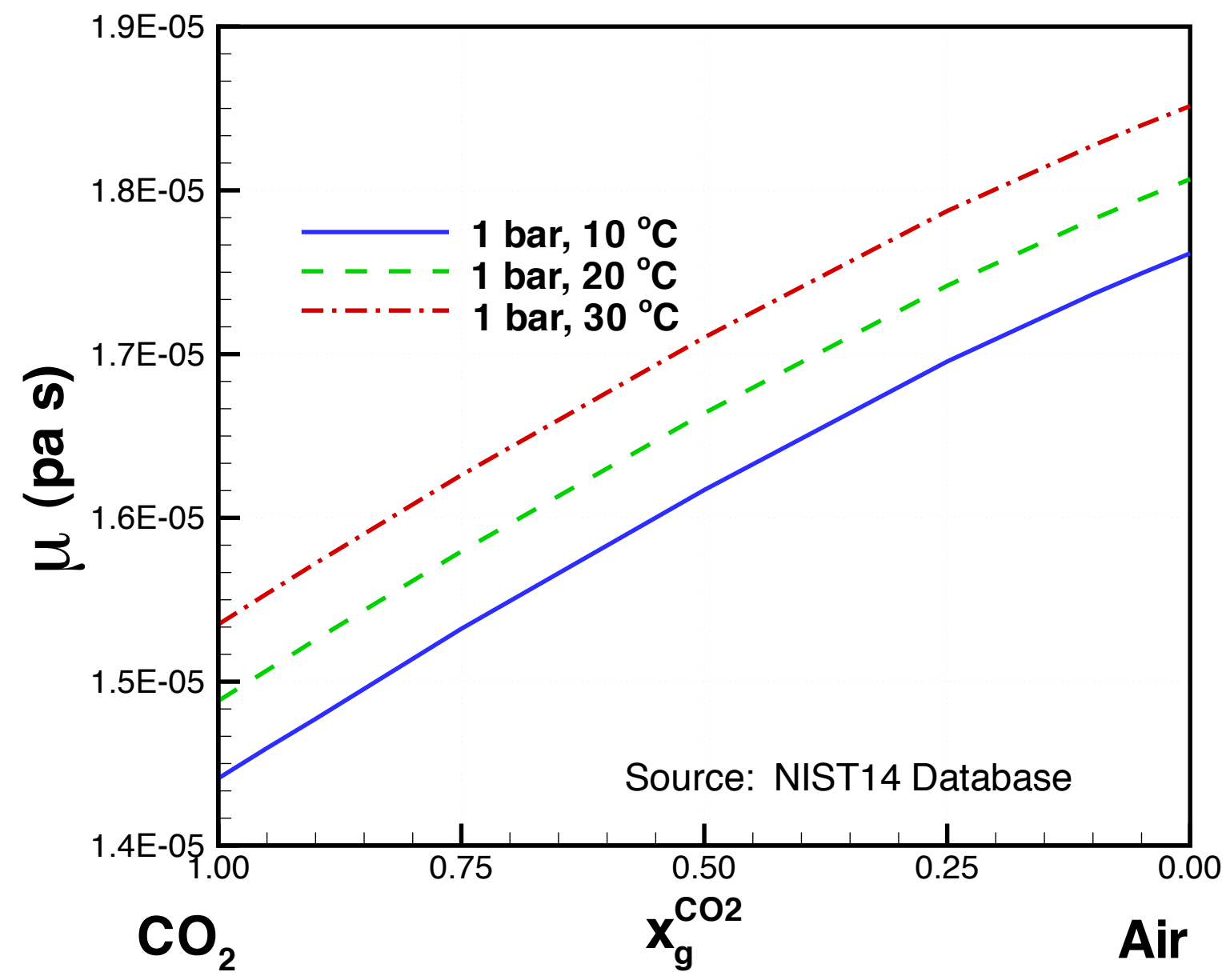

Figure 2.3. Viscosity as a function of concentration (mole fraction) in the system $\mathrm{CO}_{2-}$ air. 


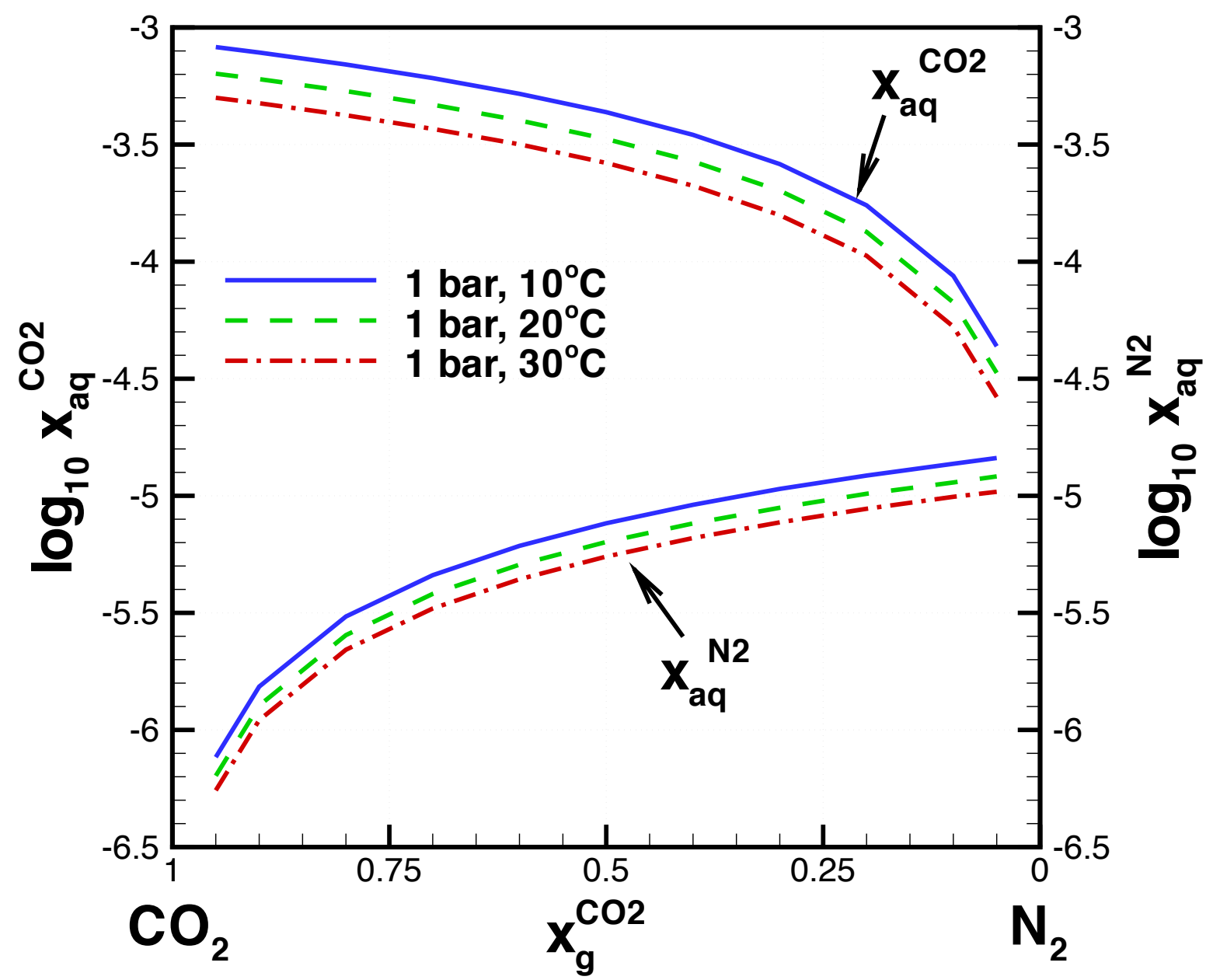

Figure 2.4. Solubility of $\mathrm{CO}_{2}$ and $\mathrm{N}_{2}$ in water (mole fraction). 

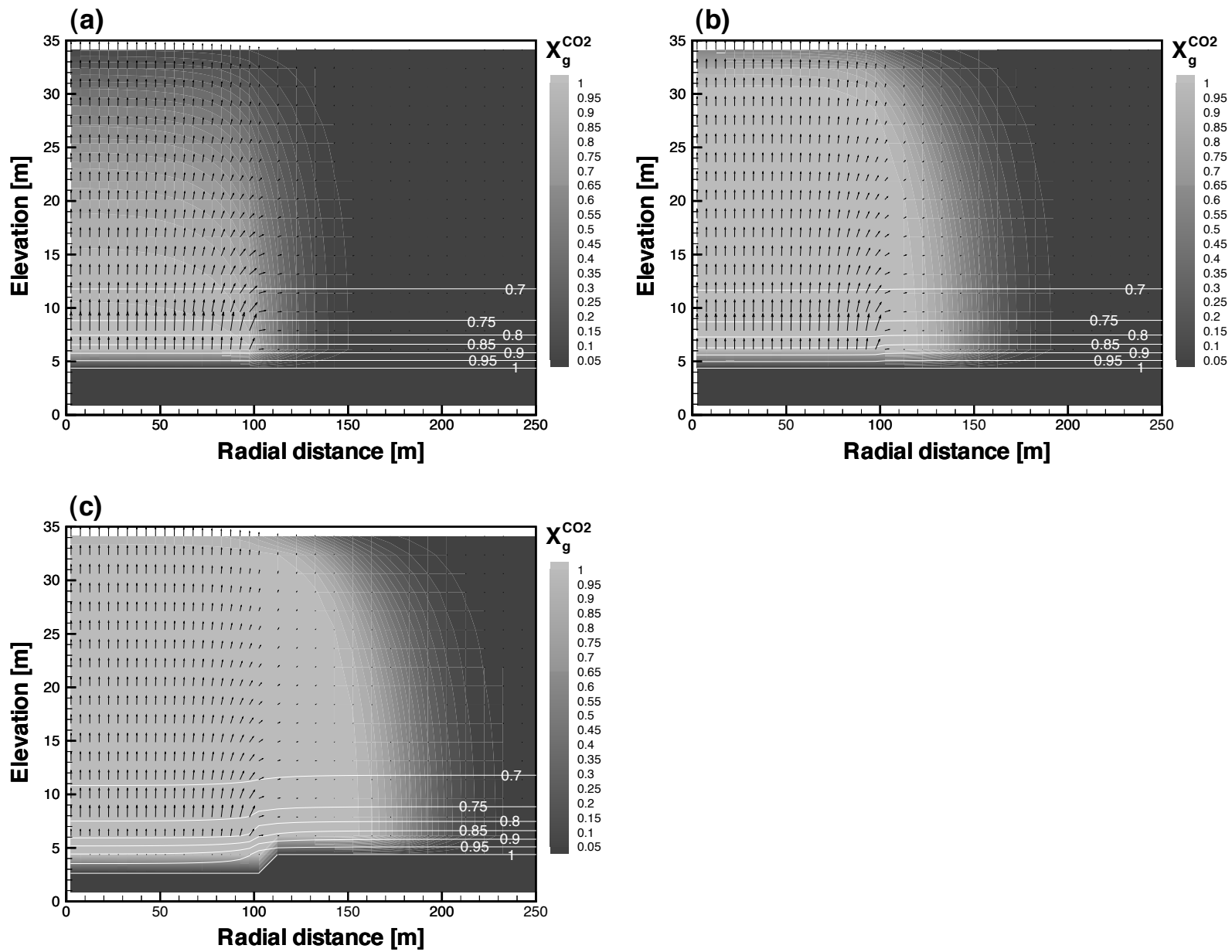

Figure 3.1. Simulation results for leakage where shading indicates mass fraction of $\mathrm{CO}_{2}$ in the gas phase, and labeled contour lines indicate water saturation, and vectors show gas phase pore velocity for steady-state leakage rates of $4 \times 10^{4}, 4 \times 10^{5}$, and $4 \times 10^{6} \mathrm{~kg} \mathrm{yr}^{-1}$. The maximum vector size represents values of approximately (a) 0.057, (b) 0.53, and (c) $3.6 \mathrm{~m} \mathrm{~d}^{-1}$. 
(a)

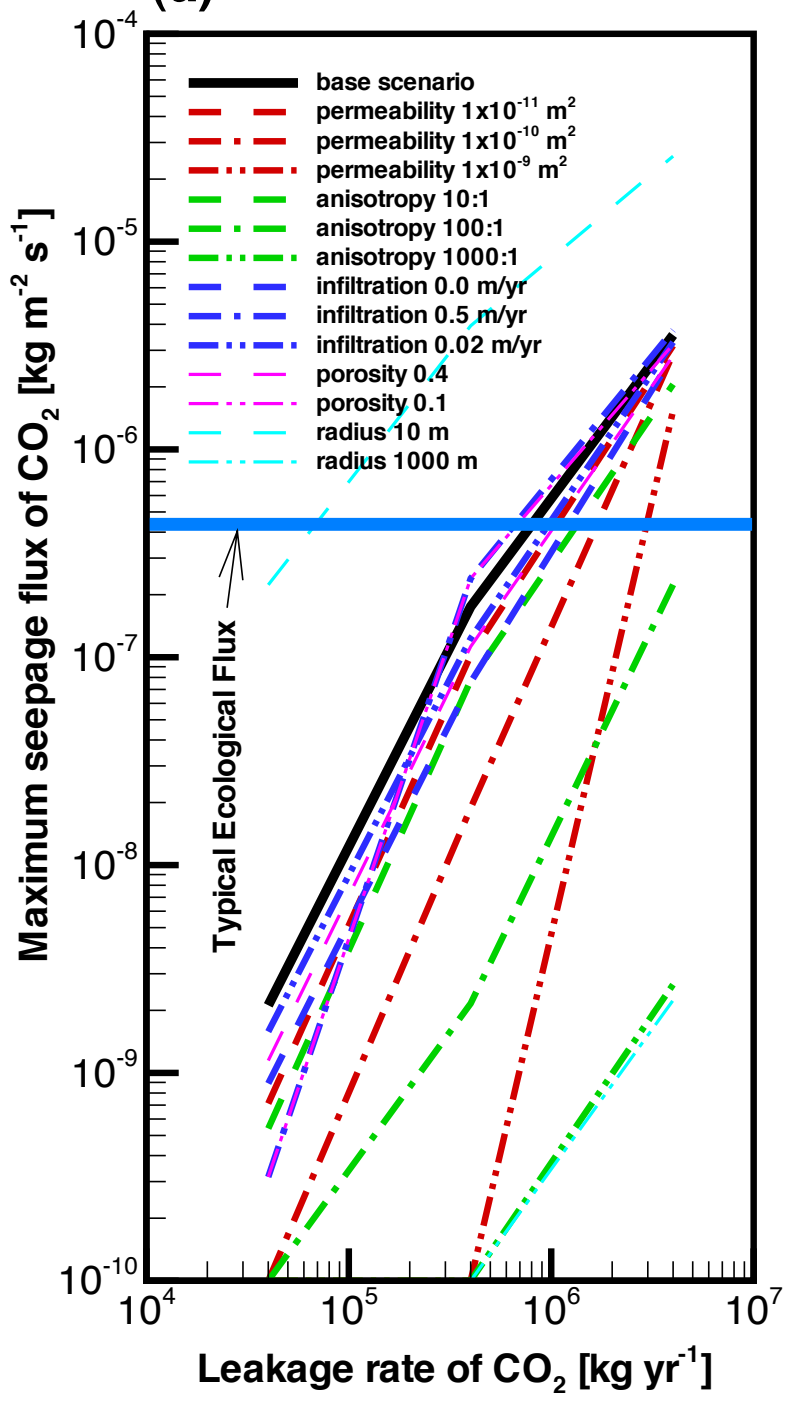

(b)

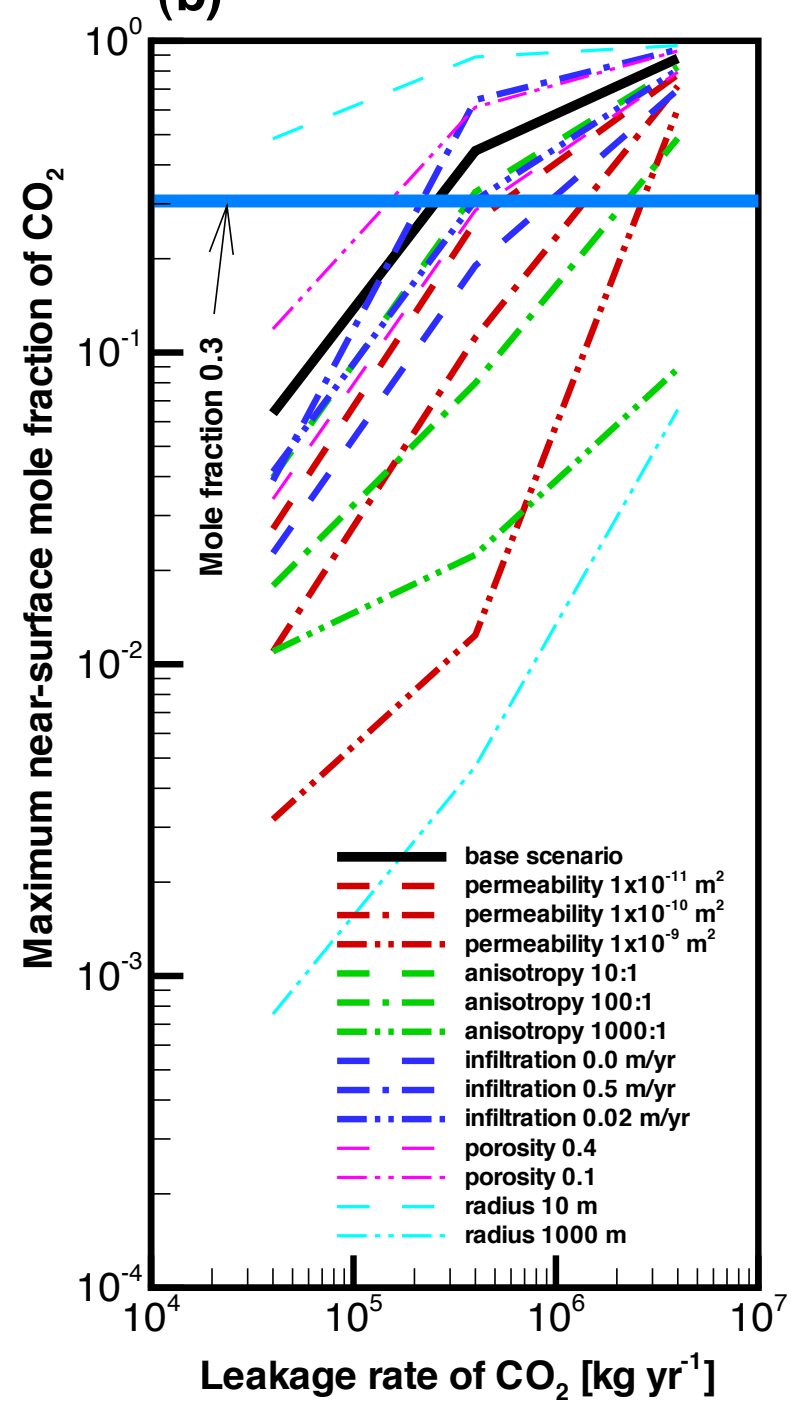

Figure 3.2. Maximum seepage flux of $\mathrm{CO}_{2}$ and maximum near-surface gas mole fraction $\mathrm{CO}_{2}$ as a function of leakage rate at steady-state seepage conditions. 
(a)

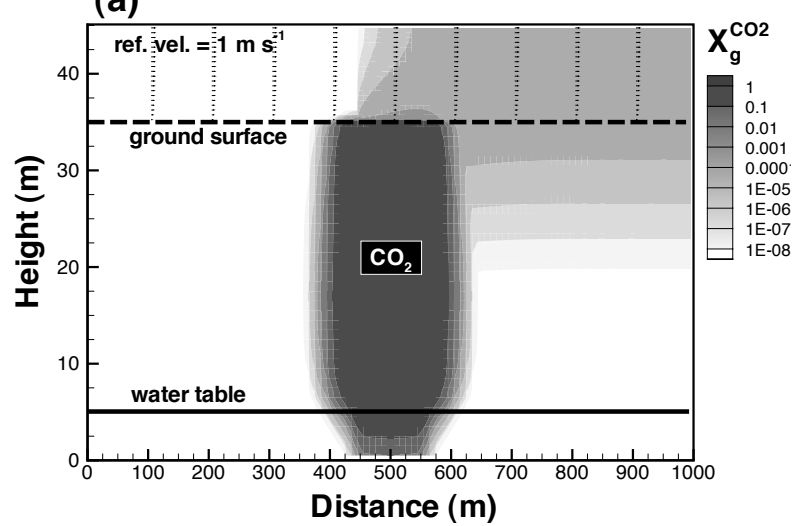

(c)

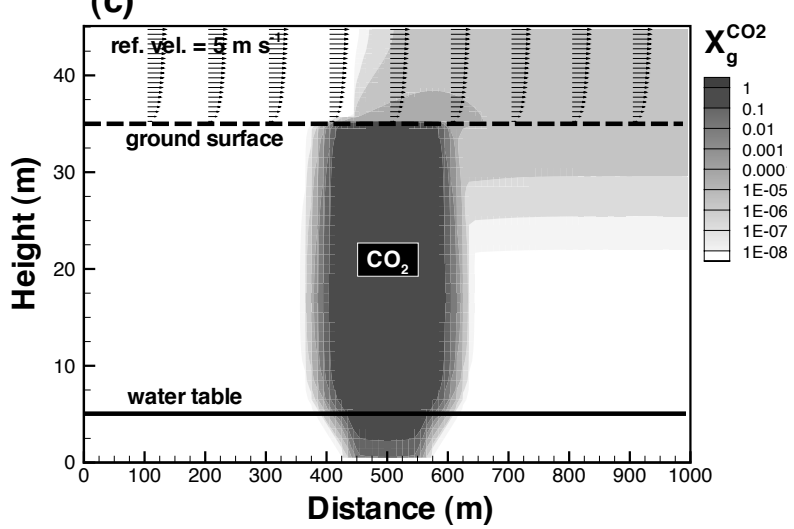

(b)

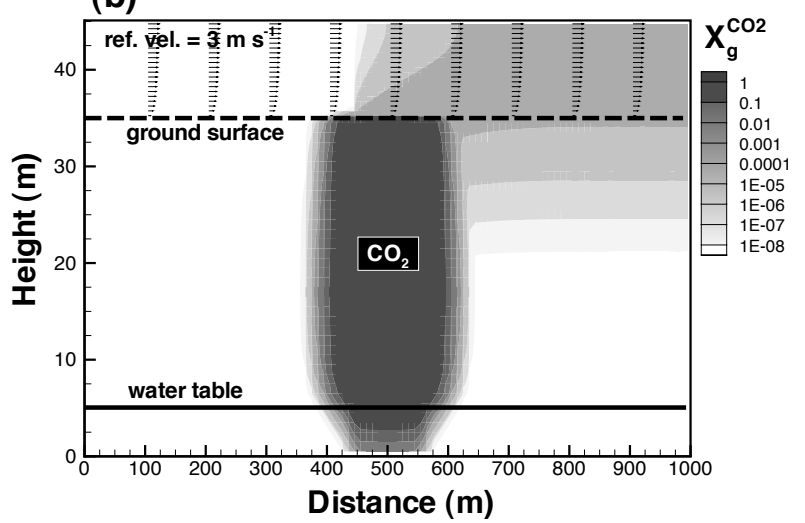

(d)

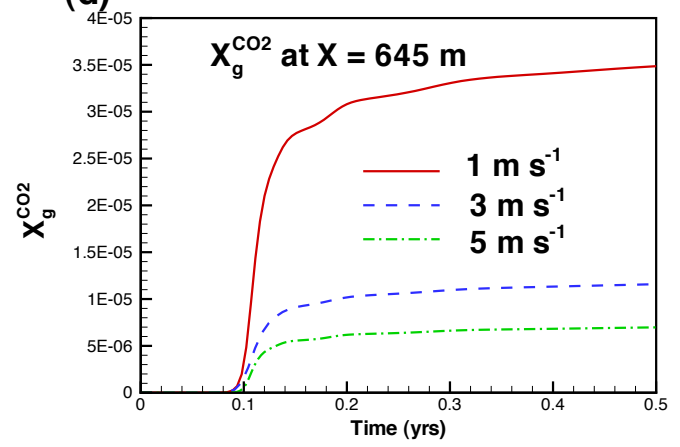

Figure 3.3. Simulation results showing mass fraction of $\mathrm{CO}_{2}$ in the gas phase and gas velocity vectors for the coupled problem. (a) wind speed $1 \mathrm{~m} \mathrm{~s}^{-1}$; (b) wind speed $3 \mathrm{~m} \mathrm{~s}^{-1}$; (c) wind speed $5 \mathrm{~m} \mathrm{~s}^{-1}$; (d) mass fraction $\mathrm{CO}_{2}$ at $x=645 \mathrm{~m}$. 


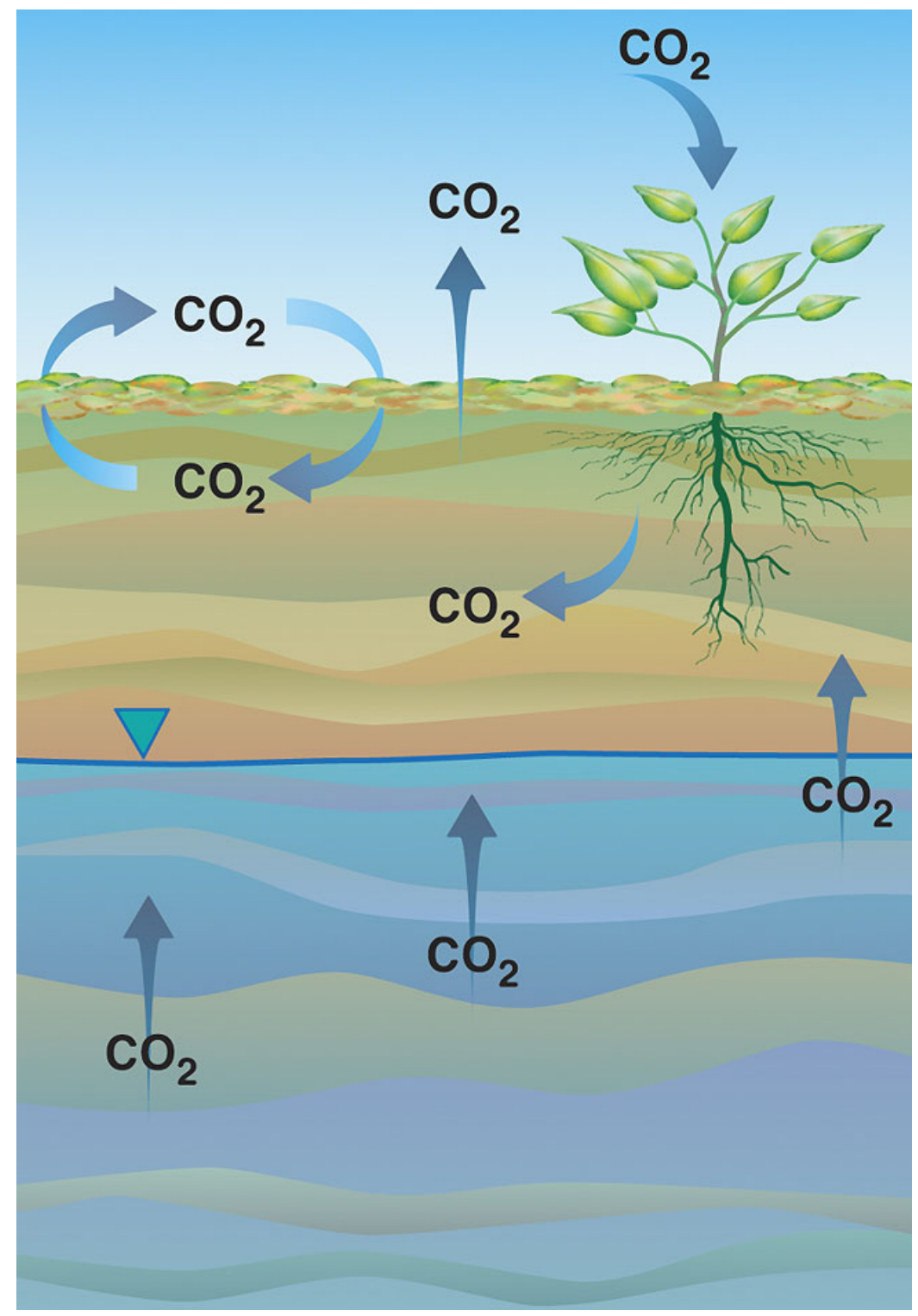

Figure 4.1. Soil $\mathrm{CO}_{2}$ sources and sinks, showing from left-right, top-bottom, exchange with the atmosphere, production from decay of organic matter such as leaf litter, uptake by plants, production by root respiration, deep degassing, release from groundwater due to depressurization, and production by oxidation of organic carbon in groundwater at the water table. 


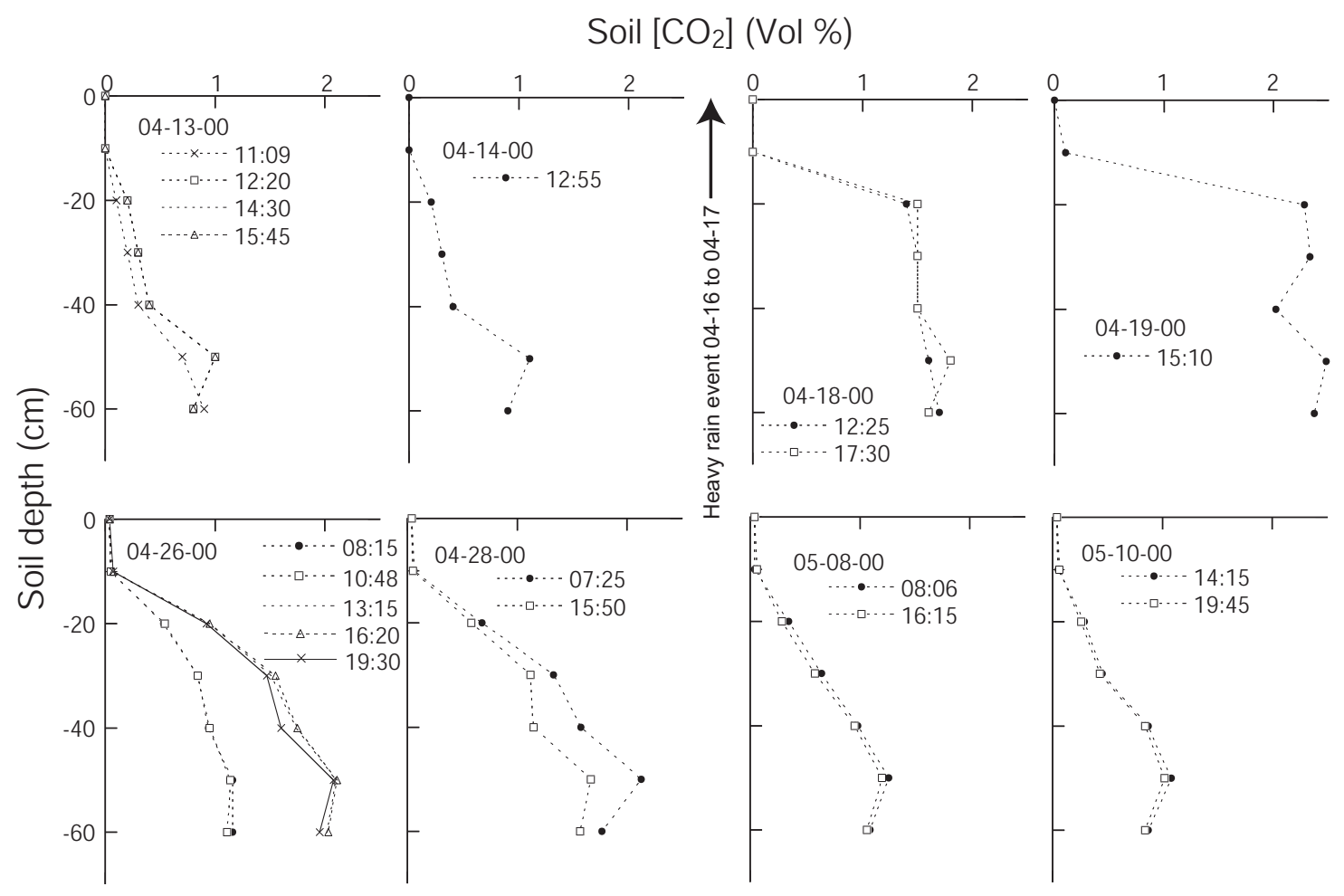

Figure 4.2. Repeated measurements of a soil $\mathrm{CO}_{2}$ concentration profile in central California over a month-long period (modified from Lewicki et al., 2003). Measurement dates and times and the timing of a heavy rain event are shown. Temporal variability of soil $\mathrm{CO}_{2}$ concentration is due to change in soil $\mathrm{CO}_{2}$ production rates related to changes in soil temperature and water content. 


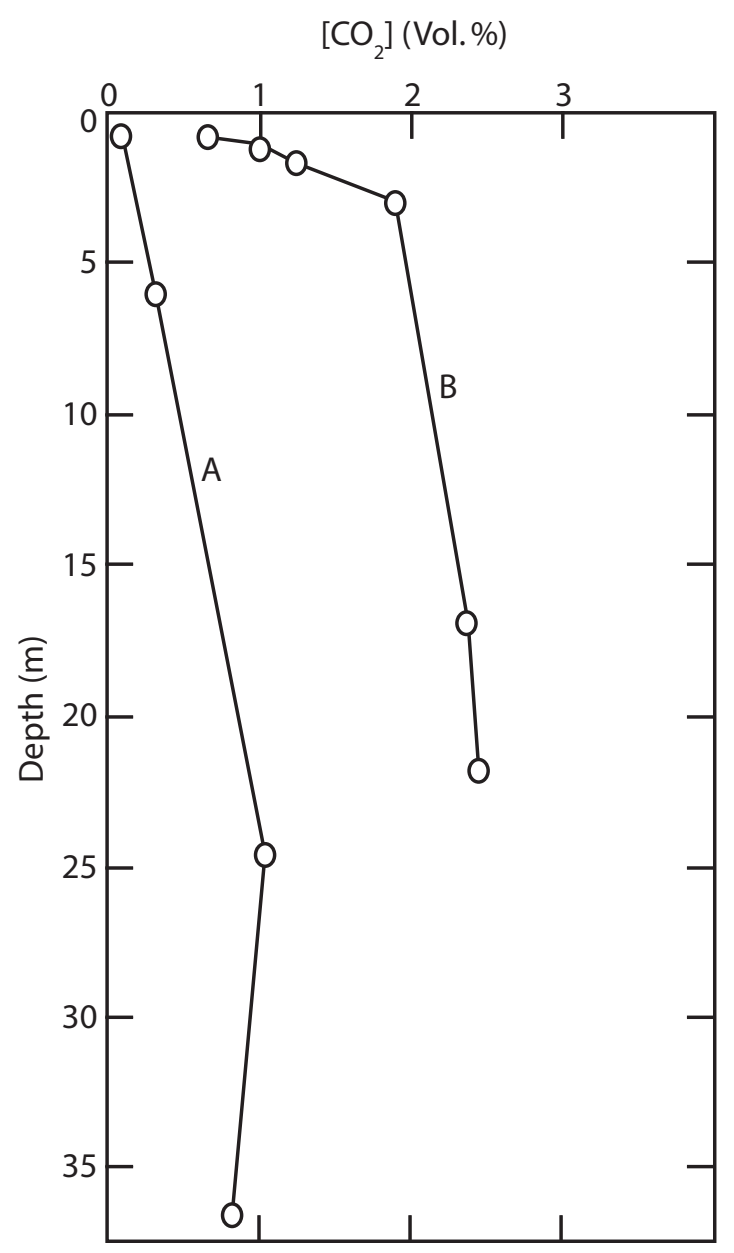

Figure 4.3. Deep $\mathrm{CO}_{2}$ concentration profiles measured at two locations ( $A$ and $B$ ) in the unsaturated zone above the Ogallala aquifer system of Texas (modified from Wood and Petraitis, 1984). Increase in $\mathrm{CO}_{2}$ concentration with depth was interpreted to reflect production of $\mathrm{CO}_{2}$ by microbial oxidation of particulate organic carbon. 


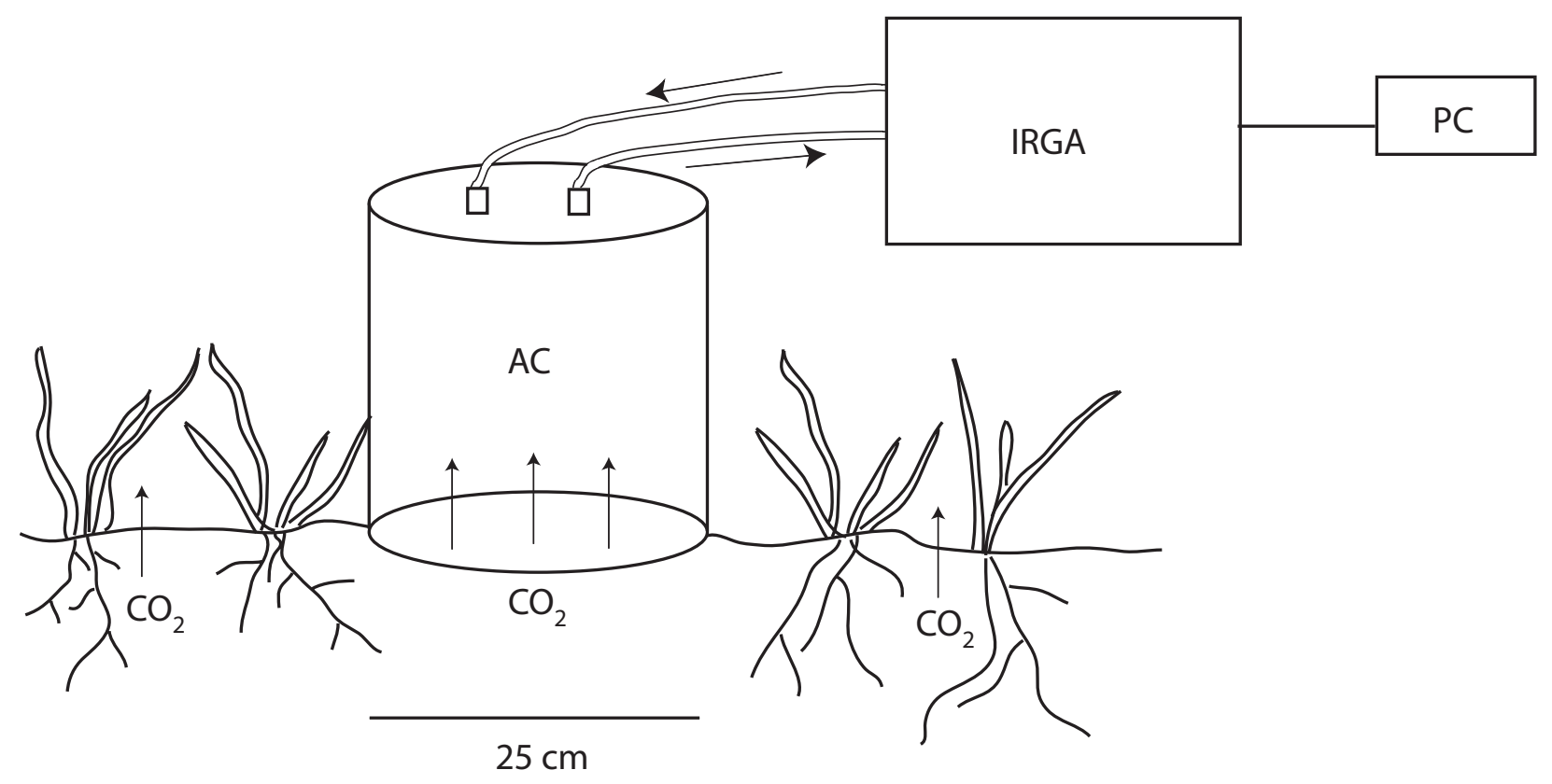

Figure 5.1. Sketch of the accumulation chamber (AC) measurement system of soil $\mathrm{CO}_{2}$ flux. Contained air is circulated through the AC and the IRGA and the rate of change of $\mathrm{CO}_{2}$ concentration in the $A C$ is measured by the IRGA and recorded by the PC. 


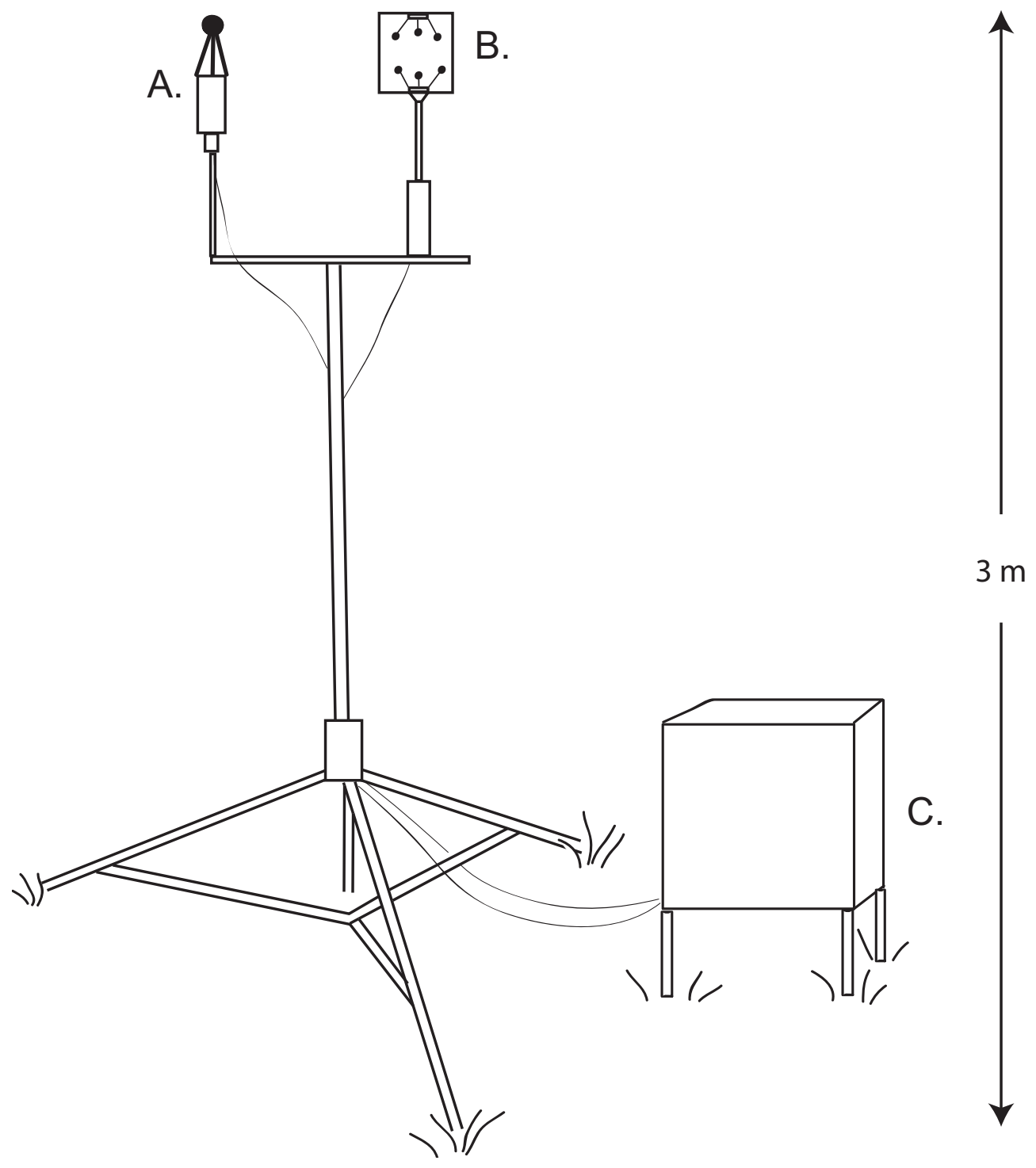

Figure 5.2. Sketch of eddy correlation (EC) instrumentation tower showing (A) open path IRGA), (B) high frequency response sonic anemometer, and $(C)$ box containing power source and datalogger/PC. 


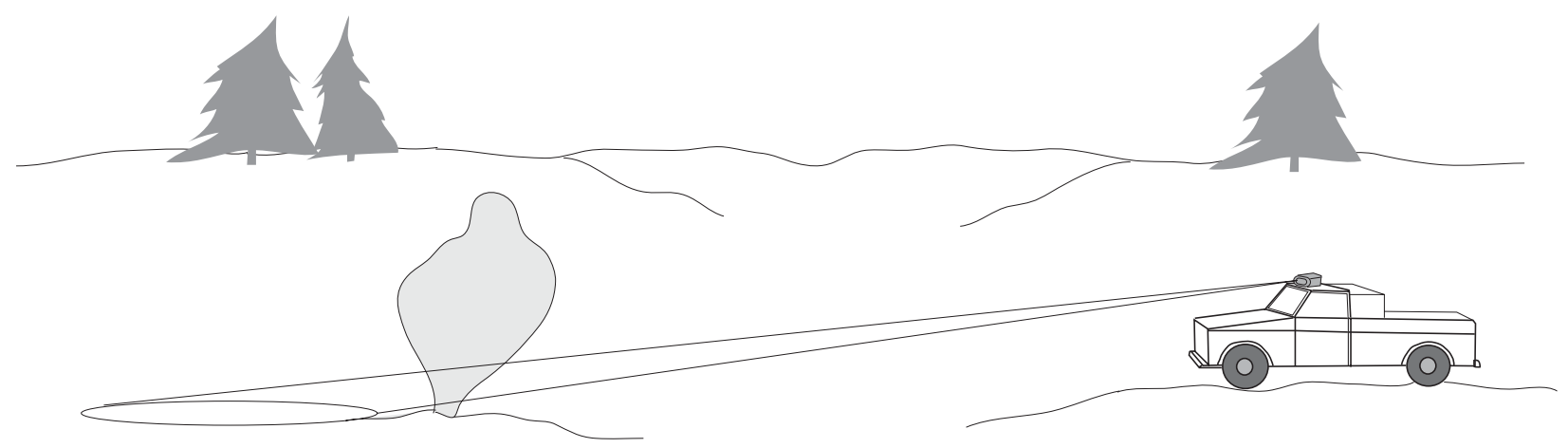

Figure 5.3. Sketch of truck-mounted LIDAR system and seepage plume. 


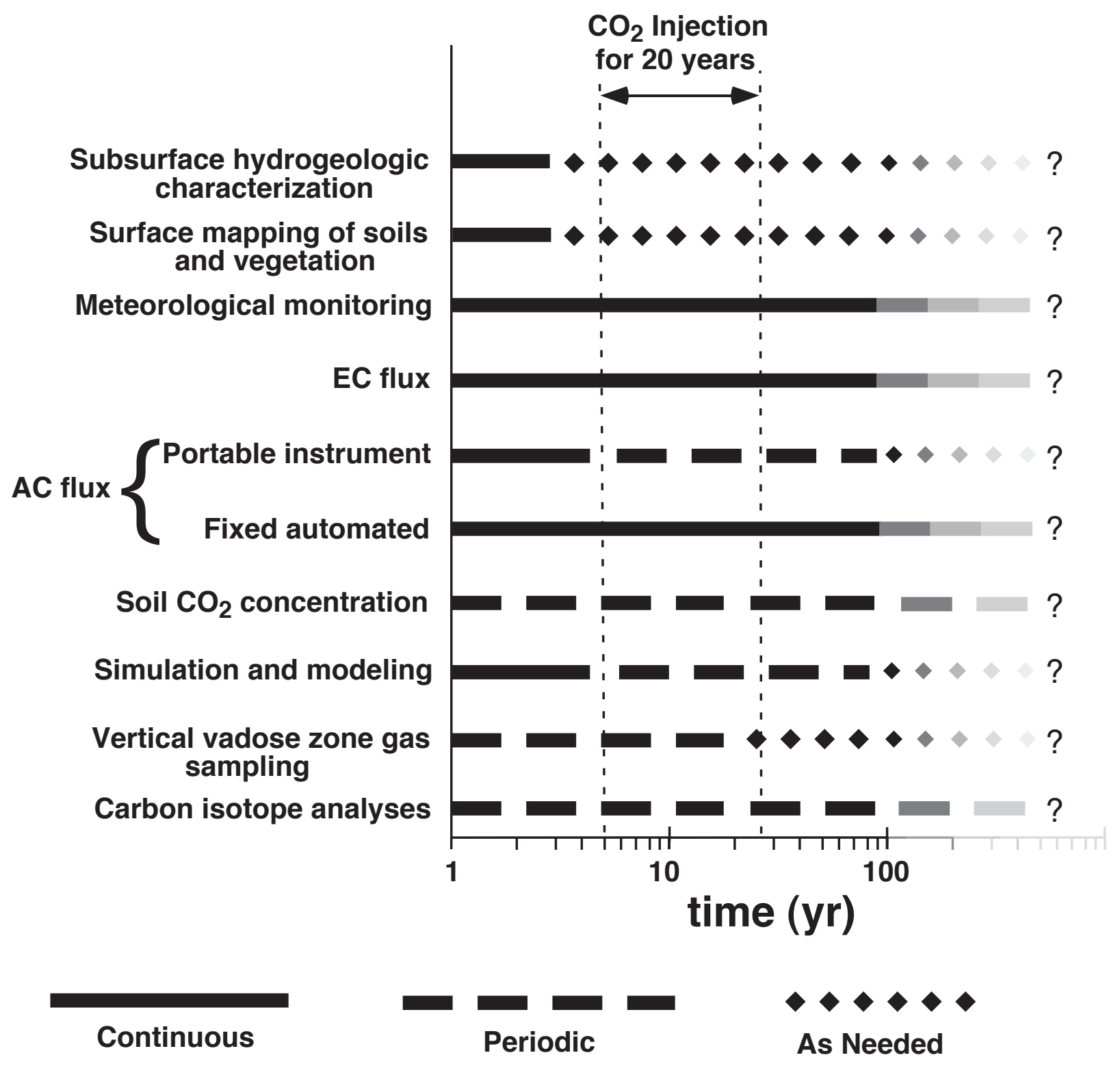

Figure 6.1. Example activity and schedule chart for $\mathrm{CO}_{2} \mathrm{LOSS}$ detection and monitoring showing generalized frequency of measurements (i.e., continuous, periodic, as needed) over time preceeding, during, and following $\mathrm{CO}_{2}$ injection. Lighter shading indicates increasing uncertainty in need for activities at long times following injection. 